\title{
Migrantes en la ciudad. Un análisis demográfico de la inmigración en la ciudad de Buenos Aires en el contexto de la guerra con el Brasil (1827)
}

Luis Pablo Dmitruk

Universidad de Buenos Aires, Argentina

luispablodmi@yahoo.com.ar

Artículo recibido: 24 de mayo de 2018. Aprobación final: 14 de noviembre de 2018 .

\section{Resumen}

En el complicado contexto de la guerra con el Brasil, no sólo se vio afectada la economía de la ciudad de Buenos Aires, sino también la estructura de su población. Estando ausentes como soldados una buena parte de los varones nativos en edad activa, los inmigrantes cobraron relevancia. En este trabajo vamos a develar la importancia de la población inmigrante, así como también de sus diferentes características sociodemográficas.

Palabras clave: Demografía Histórica; migraciones; Buenos Aires.

Migrants in the City. A Demographic Analysis of Immigrants in Buenos Aires City in the context of the war with Brazil (1827).

\begin{abstract}
During the complicated background of war against Brazil, not only the economy of Buenos Aires City was affected, but also its demographic population `s structure. Being absent as soldiers a large part of native-born males in active ages, the immigrants gained relevance. In this article we will reveal the importance of the immigrant population, as well as its different socio-demographic characteristics.
\end{abstract}




\section{Introducción ${ }^{1}$}

Al igual que la de su campaña, la población de la ciudad de Buenos Aires se incrementó de manera significativa a partir del siglo XVIII. Si bien el crecimiento natural tuvo participación, fue la afluencia de inmigrantes ${ }^{2}$ el factor fundamental para poder explicar el aumento demográfico de la ciudad (Ravignani, 1919; Besio Moreno, 1939; Moreno, 1965; Recchini de Lattes, 1971; García Belsunce, 1976; Johnson, 1979; Johnson y Socolow, 1980; Díaz, 1997 y 1998; Massé, 2012).

Nuestro trabajo se centra en el año 1827; las condiciones resultan algo diferentes dado que el crecimiento demográfico de la ciudad tendía a disminuir, en un entorno político en el que se entremezclan la crisis derivada del Congreso Constituyente (1824-1827) y el conflicto armado con el Imperio del Brasil (18251828). En este contexto, con una población fuertemente feminizada, la mano de obra masculina inmigrante se volvería de vital importancia para la economía de la ciudad.

A lo largo de este artículo vamos a tomar en cuenta la población inmigrante en la ciudad de Buenos Aires, intentando verificar y ampliar los resultados obtenidos en trabajos anteriores (Dmitruk, 2011;2014a; 2014b). Estos trabajos previos ofrecían una visión parcializada, dado que habíamos utilizado extractos del padrón de 1827. En esta ocasión la idea es ampliar nuestro análisis, tomando en cuenta la totalidad del registro. ${ }^{3}$

En torno al presente trabajo nos surgen una serie de preguntas: ¿Cuál es la importancia real de la inmigración en una etapa anterior a la masiva llegada de inmigrantes de fines del siglo XIX? ¿Qué papel cumplían los inmigrantes en la economía de la ciudad? ¿Cuál era la relevancia de cada comunidad inmigrante?

La problemática resulta de interés debido a que se trata de un padrón en general poco estudiado. Los padrones de la campaña de Buenos Aires del período colonial y post colonial fueron objetos de varias investigaciones ${ }^{4}$, y la demografía de la segunda parte del siglo XIX es más conocida debido a los primeros censos nacionales de población -en 1869 y 1895- (República Argentina, 1872; 1898), que junto con la creación del registro civil (1884) permitieron contar con una bibliografía más profusa en la temática (Somoza, 1971; Recchini de Lattes, 1971; Pantelides, 1992; Massé, 1992; 2012; Mazzeo, 1993; Otero, 2007).

1 Agradezco a Gladys Massé, Tomás Guzmán y Marina Sacco por su colaboración en el desarrollo de este trabajo. Agradezco también por sus aportes a los evaluadores anónimos y editores del Boletín del Instituto de Historia Argentina y Americana "Dr. Emilio Ravignani".

2 Decidimos considerar a los inmigrantes en su acepción clásica del término, de modo que denominaremos así a toda persona que haya sido registrada por el amanuense con un lugar de nacimiento distinto a la Ciudad de Buenos Aires.

3 Si bien el padrón contiene datos de la Ciudad y la Campaña, decidimos dejar de lado la Campaña para abocarnos únicamente al estudio de la Ciudad.

4 Por solo nombrar algunos: Garavaglia y Moreno (1993); Mateo (1993 y 1999); Moreno y Mateo (1997); Gelman (1998); Garavaglia (1999); Santilli (2000). 
Por otra parte, la gran afluencia inmigratoria de la segunda mitad del siglo XIX generó un tema en común para muchos investigadores (Bjerg y Otero, 1995; Devoto y Benencia, 2003; Otero, 2004; Massé, 2006; Devoto, 2007).

No obstante, y más allá de algunos análisis parciales (Szuchman, 1988; Andrews, 1989; Di Meglio, 2006; Guzmán, 2012; Dmitruk, 2011; 2014a; 2014b), el padrón de 1827 permanece relativamente poco estudiado y con muchos puntos oscuros que estamos intentando develar. En este sentido, el objetivo del presente artículo consiste en definir las características y relevancia de la población inmigrante tanto en comparación con la población nativa como en relación a las distintas categorías del grupo inmigrante. Para ello, completamos, en primer lugar, una etapa de relevamiento del padrón de la ciudad y campaña de Buenos Aires a partir de tomas fotográficas realizadas en el Archivo General de la Nación. Luego, volcamos los datos obtenidos a una base de datos, compuesta por 42.554 individuos.

Vamos a contemplar como unidad de análisis a la población, lo cual nos permitirá establecer el contexto sociodemográfico de la ciudad y describir las principales características de la población inmigrante. De este modo, nuestro análisis se centrará en aspectos cuantitativos utilizando indicadores demográficos y distribuciones porcentuales presentados en gráficos y tablas.

\section{La fuente}

La fuente a utilizar será el padrón de la ciudad y campaña de Buenos Aires, levantado entre los meses de agosto y septiembre de $1827 .{ }^{5}$ Si bien no pudimos encontrar información adecuada respecto de las razones del empadronamiento, tomando en cuenta el contexto bélico de la época, podemos arriesgar que la principal motivación sería establecer la cantidad de hombres en edad de portar armas con los que contaban la ciudad y la campaña de Buenos Aires.

Uno de los principales problemas que presenta el padrón es que no permite realizar una estimación concreta de la población porteña en 1827, debido a que faltan localizar dos cuarteles y varias manzanas dentro de otros cuarteles. ${ }^{6}$

Con respecto al formato del padrón, debemos mencionar que cuenta con planillas impresas, lo que le otorga un mayor grado de organización y previsibilidad a la información, en comparación con padrones anteriores (1744, 1778, 1806-1807 y 1810). Las variables que incluye son: sexo, nombre y apellido, color -blanco, pardo, moreno, indio, etc.-, edad, condición jurídica -libre o esclavo-, origen, estado civil, oficio y años de residencia en la ciudad -para los inmigrantes-. Otra variable interesante que podemos mencionar es la información sobre si la persona ha tenido viruela o si fue vacunada. Por otra parte, un avance importante con

5 Archivo General de la Nación (AGN), Sala X 23-5-5 y 23-5-6.

6 Para un análisis más detallado de la calidad del padrón, ver Dmitruk (2017). 
respecto a registros mencionados es la delimitación exacta de cada casa mediante la inclusión del nombre de la calle y la numeración correspondiente. ${ }^{7}$ Las distintas variables se van completando con preguntas abiertas, es decir, que no cuenta con opciones preconcebidas que el censista debía marcar, sino que la planilla se completaba anotando en un renglón la respuesta del entrevistado. De este modo observamos, como es de esperar, una estructura más cercana a un empadronamiento que a los censos modernos del siglo XX.

Por lo demás, un inconveniente que detectamos es que no está explicitada la relación con el jefe de familia; no obstante, puede ser inferida a partir de otras variables: nombre y apellido, sexo, edad y estado civil. La información sobre la ocupación es bastante irregular, dado que el amanuense se ocupaba de relevar básicamente a los jefes de familia, por lo que el resto de los integrantes del hogar se encuentran sub registrados ${ }^{8}$, especialmente en el caso de las mujeres.

\section{La ciudad de Buenos Aires en 1827}

Hacia 1827 la ciudad se encontraba en un contexto caracterizado por la conflictividad política en el frente interno, y la guerra con el Brasil en el externo. En 1824 se convocó el congreso constituyente, a la luz de la etapa conocida como: "Feliz Experiencia". El congreso estaría signado por la polémica en torno a la soberanía, ya que mientras que para las provincias la soberanía estaba en los pueblos, para la nación el soberano era el poder central. En 1826 se aprobaría la constitución, cuyos rasgos unitarios aparecieron atenuados por ciertas concesiones a las provincias. No obstante su aprobación en general en el congreso, las provincias rechazarían la constitución y las negociaciones con el poder central finalmente fracasarían (Ternavasio, 2000: 181-187). Como corolario, el congreso no lograría sobrevivir a las disidencias entre las provincias y el poder central, al resquebrajamiento del sector dirigente de Buenos Aires y el fracasado intento de paz con el Brasil, por lo que va sería disuelto en agosto de 1827. El presidente Vicente López renunciaría y se disolvería el poder central.

7 Debemos aclarar que la numeración de las calles se registró en las zonas más densamente pobladas, mientras que en los cuarteles más alejados del centro de la ciudad y los correspondientes a la campaña, solo figura el nombre de la calle sin numeración. En algunos cuarteles periféricos no aparece ni siquiera el nombre de la calle, sino que se utiliza directamente el nombre del dueño de la casa como referencia.

8 En las planillas censales se observa, en términos generales, que el censista se encargaba de relevar la ocupación del jefe de familia, mientras que habitualmente no relevaba la ocupación de otros componentes del hogar, particularmente de las mujeres. De esta manera se incurría en un error de contenido; es decir, la persona estaba bien registrada, pero no así determinadas características (en este caso, la ocupación).

9 La Feliz Experiencia se extendió desde fines de 1820 hasta el estallido de la guerra con el Brasil, en 1825. Durante esta etapa se destacaron las ideas del liberalismo, tanto político como económico, siendo la principal figura política Bernardino Rivadavia. La Feliz Experiencia no solo fue un período de expansión económica y de estabilidad política, sino también de florecimiento cultural, educativo y científico. La expansión económica genera un gran desarrollo de la actividad pecuaria, y a su vez la necesidad de nuevas tierras fomenta la expansión de la frontera con el indio, generándose de esta manera un "círculo virtuoso" (Halperin Donghi, 1985: 210) 
La guerra con el Imperio del Brasil se inició en 1825, aunque tuvo como antecedente la intervención del Imperio Luso-brasileño en la Banda Oriental desde 1816. En un primer momento los gobiernos centrales de las Provincias Unidas evitaron intervenir debido al recelo que les generaba Artigas, el caudillo oriental. No obstante, con el desembarco en 1825 de los Treinta y Tres Orientales en la provincia oriental y su sorpresivo éxito, la situación política cambiaría y el congreso constituyente, presionado por la opinión pública y la oposición, finalmente decretaría la incorporación de la Banda Oriental a las Provincias Unidas, declarándose de hecho la guerra con el Brasil. El conflicto generó una gran distracción de recursos, tanto humanos como materiales, lo cual a su vez ocasionó severos problemas en el sector productivo. Por otra parte, el bloqueo del puerto de Buenos Aires por parte de la flota imperial le sumó dificultades al gobierno de las Provincias Unidas, propiciando el contrabando y la especulación. Finalmente, la presión británica, la inflación y la penuria fiscal obligaron a Rivadavia a negociar la paz. ${ }^{10}$ Sin embargo, este acuerdo se tornó insostenible para la posición del poder central en el congreso constituyente, lo que obligó a Rivadavia a renunciar a su cargo en julio de 1827. Una vez desintegrado el poder central, fue el gobernador de Buenos Aires, Manuel Dorrego, quien firmó la paz en agosto de 1828 (Halperin Donghi, 1985: 194; Ternavasio, 2000: 181-187).

\section{Migrantes en la ciudad}

Si bien el periodo de la gran inmigración, entre fines del siglo XIX y principios del siglo XX generaría un cambio en cuanto al volumen de población ingresada a la Argentina, es de destacar que la ciudad de Buenos Aires recibió importantes contingentes de inmigrantes ya desde el siglo XVIII y durante la primera mitad del siglo XIX ${ }^{11}$, que luego quedaron invisibilizados por la inmigración masiva. En la introducción vimos que una cantidad importante de autores le asigna un papel relevante a la inmigración en el crecimiento de la ciudad de Buenos Aires en la etapa colonial tardía. Todos los autores que trabajaron con el padrón de 1827 (Di Meglio, 2006; Dmitruk, 2011; Guzmán, 2012), coinciden en la importancia de la población inmigrante, proveniente particularmente de Europa -España, sobre todo-, el interior de las Provincias Unidas y África.

En esta sección vamos a analizar las diversas características que nos permite relevar el padrón de 1827 en torno a la población inmigrante: su relación con respecto a población total, las principales categorías, las regiones de donde

10 Ante las presiones, Rivadavia comisionó al ministro Manuel García para firmar la paz con el Brasil, no obstante, García se habría extralimitado en sus funciones y firmó la paz en términos que fueron considerados ignominiosos por el Congreso Constituyente. De hecho, el tratado consideraba la sesión de la Banda Oriental y el pago de un resarcimiento económico al Imperio del Brasil. El Congreso rechazó el acuerdo, lo que derivó en la renuncia de Rivadavia y en la continuidad de la guerra durante un año más. 
provenían, estructura de sexo y edad, edad media y mediana, distribución espacial en las distintas zonas de la ciudad, estructura socio ocupacional y años de residencia.

En primer lugar nos vamos a abocar a la diferencia entre la población nativa y la población inmigrante, para luego analizar cada categoría de origen inmigrante: europeos, inmigrantes internos, africanos e inmigrantes limítrofes.

Como anteriormente mencionamos, entendemos por inmigrante a toda persona nacida fuera de la ciudad de Buenos Aires. Según el padrón de 1827, los inmigrantes conformaban más de un cuarto de la población de la ciudad (29\%), totalizando 11.915 personas (Gráfico 1), números esperables en una ciudad típicamente cosmopolita que oficiaba como centro administrativo y comercial, además de ser el principal puerto de entrada a lo que entonces eran las Provincias Unidas del Río de la Plata. ${ }^{12}$

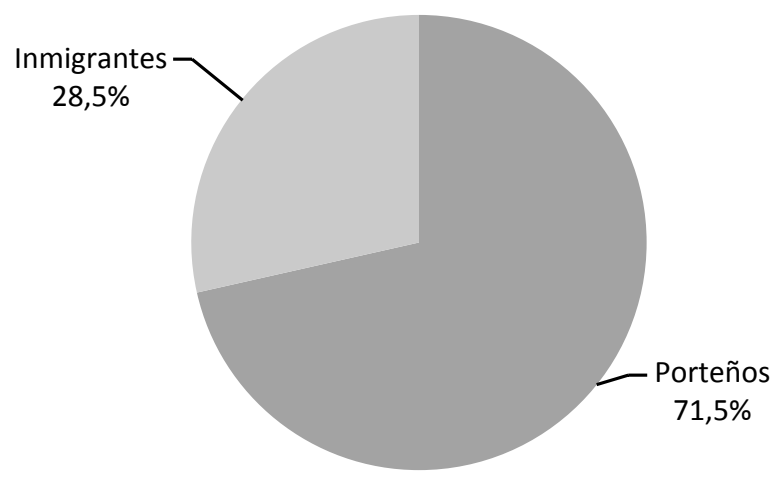

Gráfico 1. Población de la Ciudad de Buenos Aires según su origen, 1827. Fuente: Elaboración propia en base a: Archivo General de la Nación: Sala X 23-5-5 y 23-5-6. Total: 41.765. Sin datos: 789.

Con respecto a los diversos orígenes de los inmigrantes, en el Gráfico 2 podemos observar las principales categorías: europeos, inmigrantes internos y africanos, mientras que los inmigrantes limítrofes tenían una participación menor.

12 En el padrón nos encontramos con un total de 256 personas que registraron categorías de origen algo difusas, como ser "Patria" o "Criollo". Evidentemente se trataba de personas que podían ser porteños o inmigrantes internos, por lo que para poder incluirlos en nuestro análisis utilizamos una distribución de ignorados, bajo el supuesto de que estas categorías se distribuyen entre porteños e inmigrantes internos de manera similar a la que se distribuyen estas mismas categorías en el total de la población. 


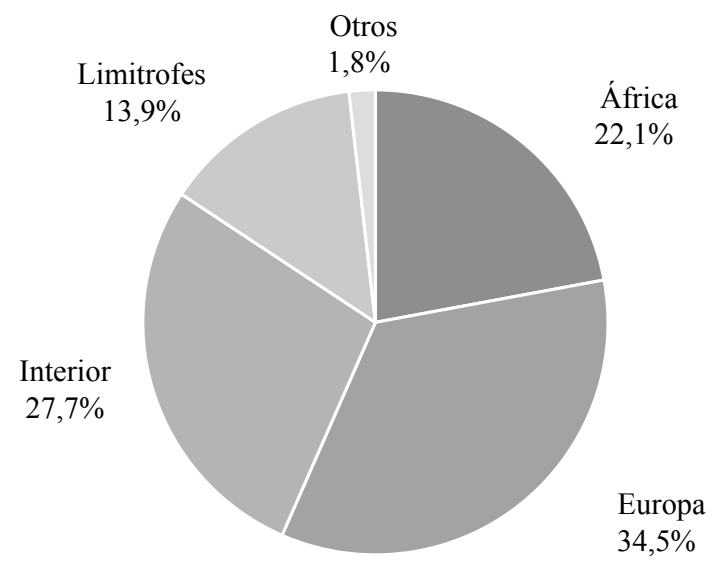

Gráfico 2. Población inmigrante de la Ciudad de Buenos Aires según su origen, 1827. Fuente: Elaboración propia en base a: Archivo General de la Nación: Sala X 23-5-5 y 23-5-6. Total: 11.915 casos. Sin datos: 789.

* Limítrofes: corresponde a los inmigrantes originarios de los actuales países limítrofes: Uruguay, Brasil, Bolivia, Paraguay y Chile.

**Otros: corresponde a la población que no puede sumarse a ninguna de las demás categorías. Sería una categorías "residual". En su mayoría, se trataba de personas nacidas en el continente americano: estadounidenses, peruanos y cubanos, aunque también hemos observado la presencia población originaria del continente asiático.

Los europeos conformaban la categoría de mayor número relativo entre los inmigrantes. Se trataba de europeos de distintos países y de diferentes sectores socio ocupacionales que arribaban a la ciudad en busca de mejores oportunidades. Los españoles representaban el principal origen dentro de esta categoría, conformando una cifra superior al 40\% del total. Luego de la independencia, el fin del monopolio comercial y el crecimiento de un clima social antipeninsular generaron como consecuencia que los españoles dejaran de migrar hacía el Río de la Plata (Halperin Donghi, 1979: 176). No obstante, la importancia de su número nos indica que todavía representaban una comunidad relevante en la sociedad porteña. Además de los españoles, tenían participación relevante los ingleses, franceses, e italianos, que a partir de 1810 fueron aumentando su número de manera considerable.

Los inmigrantes provenientes del interior de las Provincias Unidas representaban el segundo grupo en importancia. Evidentemente la ciudad de Buenos Aires era un foco de atracción para los migrantes internos que buscaban mejores alternativas; de hecho, lo era incluso desde el siglo XVIII, pero su número relativo y absoluto pareció ir in crescendo durante el siglo XIX (Massé, 1992: 184-186; Díaz, 1997 y 1998: 11-19).

Los africanos, por su parte, conformaban el tercer grupo migratorio en importancia. En gran parte se trataba de esclavos ${ }^{13}$ o libertos que sirven en el servicio doméstico y el trabajo manual calificado y no calificado. Más allá del auge de las ideas libertarias y de que el comercio de esclavos disminuyendo a partir de la independencia, todavía en 1827 los africanos continuaban siendo un componente importante de la población inmigrante.

13 El hecho de incluir a los esclavos como inmigrantes es un tanto polémico, dado que este grupo migró de manera obligada. No obstante cumple con nuestro requisito metodológico de haber nacido fuera de la ciudad de Buenos Aires, por lo que decidimos considerarlos inmigrantes, forzados, pero inmigrantes al fin. 
Los inmigrantes provenientes de los actuales países limítrofes tenían una importancia menor, siendo los orientales la comunidad principal. La categoría "Otros" por su parte, no alcanzaba el $2 \%$ del total y estaba conformada principalmente por estadounidenses y peruanos.

\section{Nativos e inmigrantes...}

\section{Estructura de la población nativa e inmigrante según sexo y edad}

En esta sección vamos a analizar la estructura de sexos y edad de la población, tomando en cuenta a los nativos y a los inmigrantes por separado. En la Tabla 1 podemos observar que la población nativa tenía una baja relación de masculinidad, derivada de los efectos de la guerra con el Brasil:ausencia de varones en edad activa debido a la leva del ejército, presente en la Banda Oriental, pero también otros efectos difíciles de cuantificar, como la huida o el ocultamiento del censista ante la sospecha de que el censo tenía por objeto reclutar soldados. ${ }^{14}$

Por el contrario, los números que revela la población inmigrante nos dan a entender una preponderancia masculina bastante marcada, aunque debemos aclarar que hacia adentro del grupo inmigrante la realidad era bastante heterogénea.

Tabla 1. Relación de Masculinidad según origen. Ciudad de Buenos Aires, 1827. Fuente: Elaboración propia en base a: Archivo General de la Nación: Sala X 23-5-5 y 23-5-6.

\begin{tabular}{cc}
\hline Origen & Relación de masculinidad \\
\hline Nativos & 61,0 \\
Inmigrantes & 163,3 \\
\hline
\end{tabular}

Total: 42.735 casos. Sin datos: 819 casos.

En la Tabla 2, que se presenta a continuación, podemos apreciar la edad media y mediana ${ }^{15}$ de la población. La población nativa de la ciudad se presentaba como una población joven, e incluso a partir de los datos de la edad mediana es posible observar que la mitad de la población nativa se encontraba compuesta por niños y adolescentes. Si bien tenemos que tomar en cuenta que gran parte de los adultos se encuentran subregistrados, también lo están los niños menores de diez años. ${ }^{16}$

14 Un análisis más pormenorizado de esta cuestión puede buscarse en Dmitruk (2017: 149-156).

El ejército se componía de militares de carrera, pero también de la leva (más o menos forzosa) proveniente de los "vagos y mal entretenidos. En las instrucciones se indicaba que los soldados deberían tener entre 17 y 45 años, preferentemente nativos y solteros. Debe aclararse que la población pasible de ser convocada a las armas no solo incluía a los porteños, sino también a los nacidos en el interior de las Provincias Unidas del Río de la Plata, orientales inclusive (Fradkin, 2006).

15 La mediana es el número que separa a la población en dos mitades. Una mitad que registra una edad inferior a la mediana y la otra que registra una edad superior a la mediana.

16 La omisión de los niños tiene que ver con una problemática común en los censos de población que es la renuencia a tratar al niño como una persona, tanto de parte del informante como del censista, de modo que es omitido en el recuento (Chackiel, 2009, junio: 5). Esta percepción es aún mayor en las sociedades pre transicionales, donde la fecundidad de la mujer era muy superior a la actual. 
Por su parte los inmigrantes contaban con un promedio de edad bastante más avanzado, que oscilaba entre los 30 y 40 años, lo cual es entendible dado que la población de niños inmigrantes era ciertamente reducida en comparación con la población nativa. Tanto entre los nativos como entre los inmigrantes, la media era algo más elevada que la mediana. ${ }^{17}$

Tabla 2. Edad media y mediana de la población según origen. Ciudad de Buenos Aires. 1827. Fuente: Elaboración propia en base a: Archivo General de la Nación: Sala X 23-5-5 y 23-5-6.

\begin{tabular}{lcc}
\hline \multicolumn{1}{c}{ Origen } & Media & Mediana \\
\hline Nativos & 22.6 & 19 \\
Inmigrantes & 35.2 & 32 \\
Total ciudad & 26.0 & 24 \\
\hline
\end{tabular}

Total: 42.334. Sin datos 220 .

El Gráfico 3 presenta la estructura según sexo y edad de la población nativa. Da cuenta de una población joven, aunque con un importante subregistro infantil. La población masculina se encontraba, como ya vimos, fuertemente afectada por la guerra con el Brasil, lo que le aporta a la pirámide su particular inclinación hacia la derecha. A su vez observamos una importante disminución de efectivos de ambos sexos a partir de los 30 años, atribuible a la baja esperanza de vida de toda sociedad pretransicional.

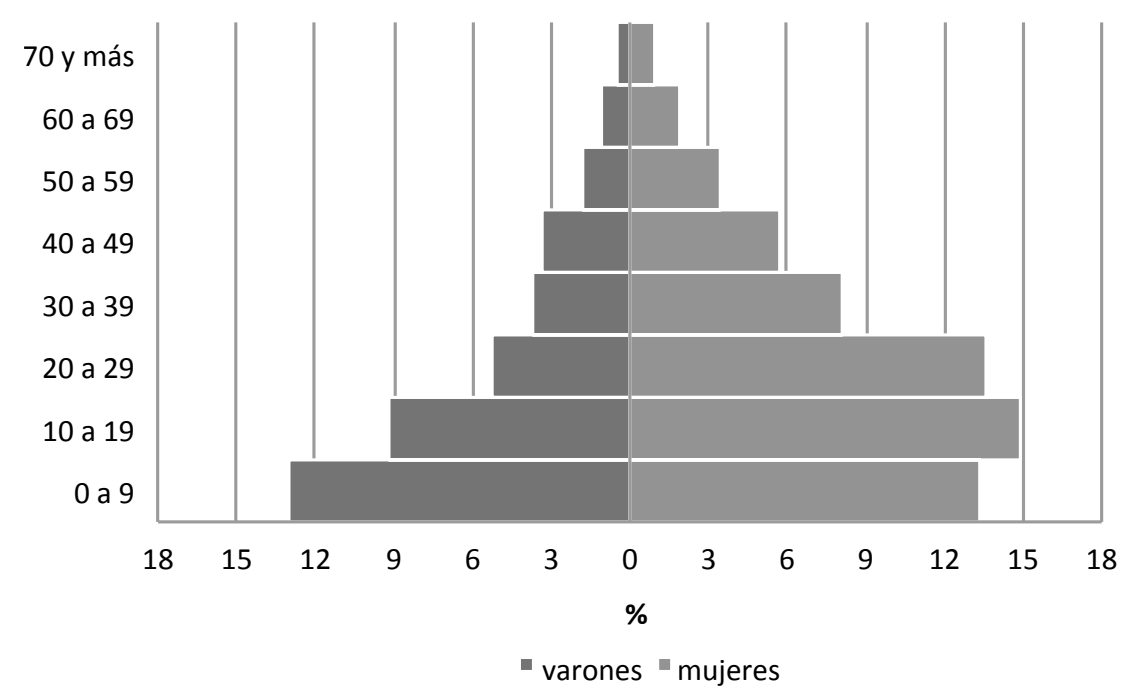

Gráfico 3. Población nacida en la Ciudad de Buenos Aires, según sexo y edad, 1827. Fuente: Elaboración propia en base a: Archivo General de la Nación: Sala X 23-5-5 y 23-5-6. Total:

29.710 casos. Sin datos: 140 casos.

En el Gráfico 4, por el contrario, la pirámide de la población de inmigrantes viene a compensar algunas de las características que apreciamos en la estructura de la población nativa. Observamos principalmente una marcada diferencia de sexos en favor de los varones, y una alta concentración de la

17 La diferencia entre la media y la mediana se produce posiblemente porque la primera medida es más sensible a las declaraciones de edad demasiado altas, por lo que el valor tiende a ser más elevado. Dicho de otra manera: las declaraciones de edad demasiado altas terminan "traccionando" hacia arriba el valor de la media. 
población en las edades activas, que en cierto modo es entendible dado que la población activa es la que más tiende a migrar en comparación con los niños y los adultos mayores.

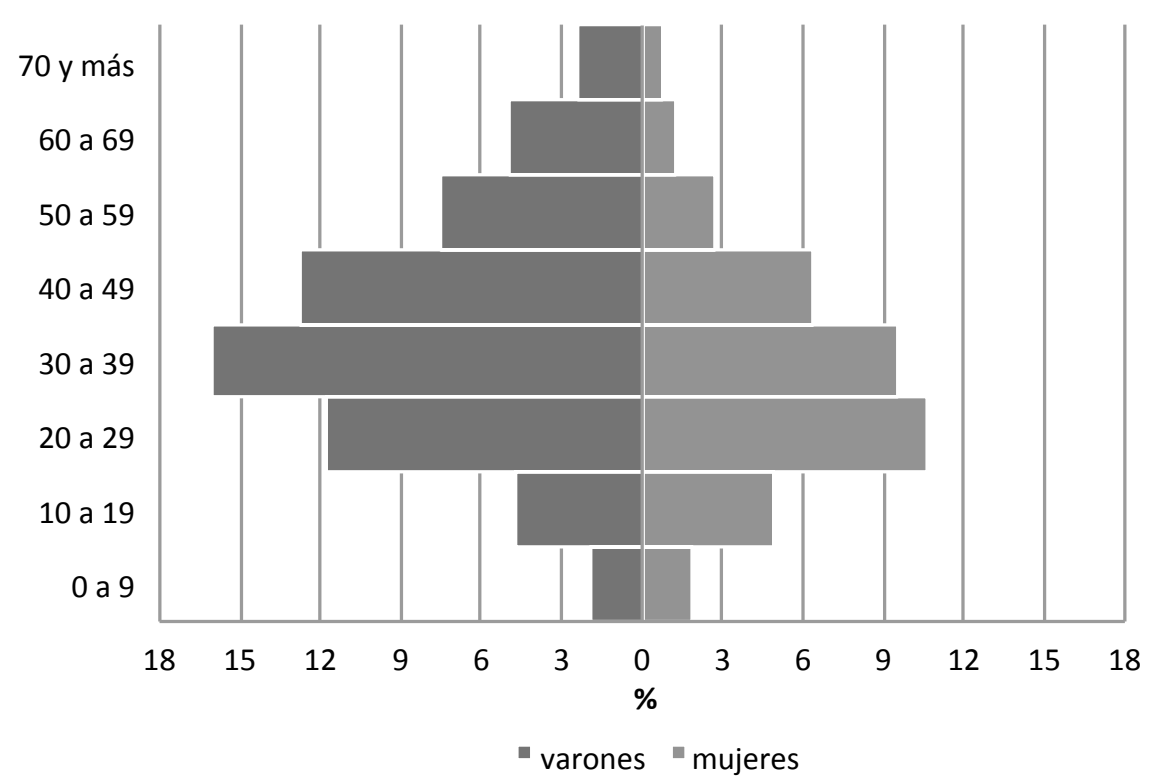

Gráfico 4. Población inmigrante según sexo y edad. Ciudad de Buenos Aires, 1827. Fuente: Elaboración propia en base a: Archivo General de la Nación: Sala X 23-5-5 y 23-5-6. Total: 11.789 casos. Sin datos: 126 casos.

\section{Distribución espacial}

Para poder establecer categorías adecuadas de la distribución de la población en la ciudad decidimos tomar en cuenta la distribución geográfica de los cuarteles (expuestas en la Imagen 1), así como también la concentración de población. De este modo creamos cuatro zonas diferentes, formadas por distintos cuarteles, que se organizan en forma de "C" una tras otra: Zona Centro, cuarteles: 2, 3, 4, 11, 12 y 13; Intermedia: 5, 6, 10, 17, 18 a 21; Periferia: 1, 7, 8, 14, 16, 23 a 29; Semi rural: $15,30,31,34,36,46,47,50,52,54$. 


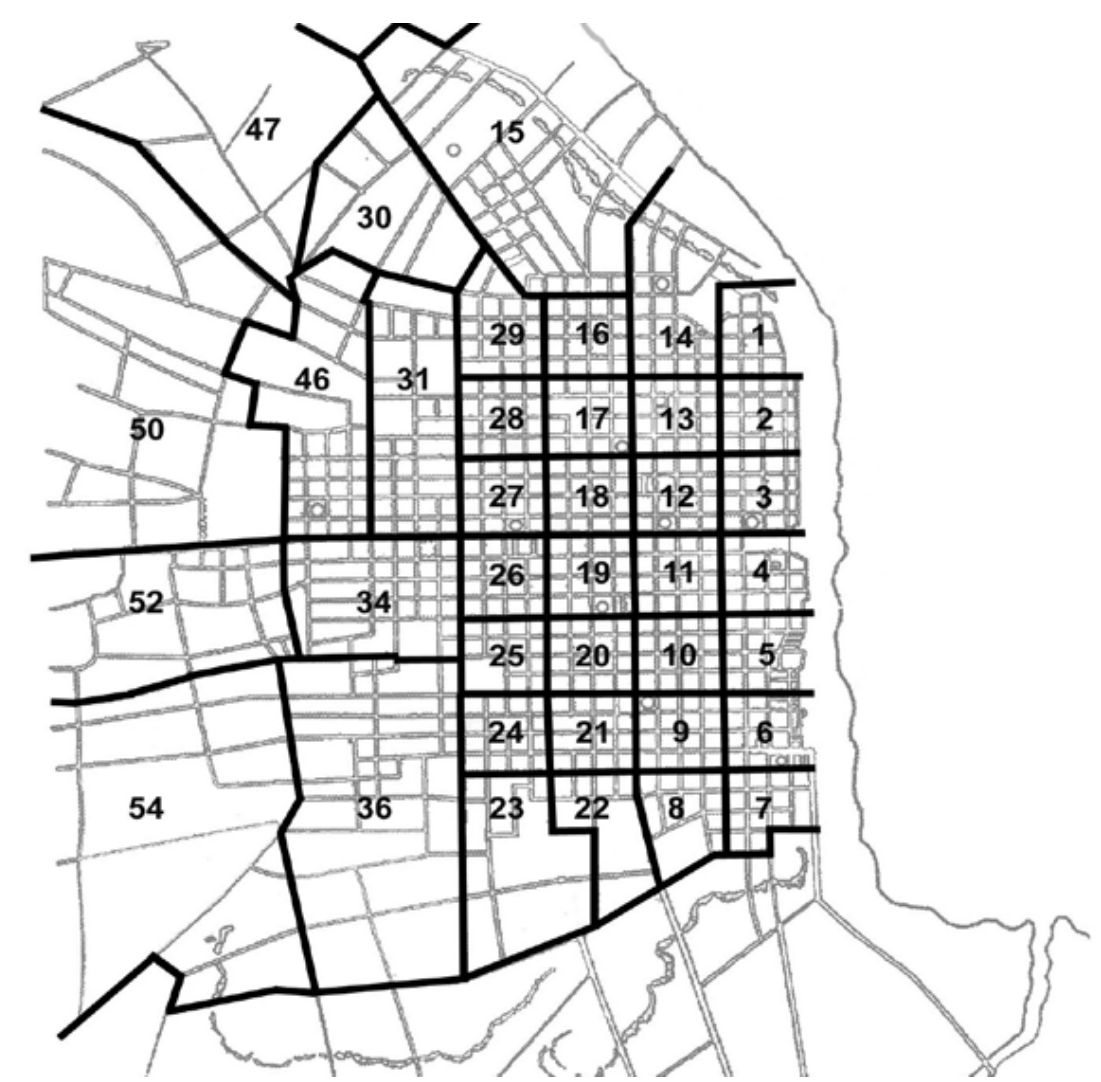

Imagen 1. Plano de los cuarteles administrativos. Ciudad de Buenos Aires. 1827. Fuente: González Bernaldo (2001)

Autores que han trabajado la distribución de la población de la ciudad de Buenos Aires mencionan que la mayor densidad demográfica se encontraba en los alrededores de la plaza central, donde estaba situado el centro económico y administrativo. Al mismo tiempo, destacan que la misma disminuía paulatinamente a medida que nos adentramos en los suburbios (Johnson y Socolow, 1980: 330; Socolow, 1982: 221; González Bernaldo, 2001: 52; Di Meglio, 2006: 29). En nuestro caso, observamos una distribución similar a la mencionada, aunque la mayor concentración se producía en un triángulo imaginario que formaban los cuarteles: 3, 11, 12 y 18, y no exactamente en la zona que rodeaba la Plaza de Mayo (límite entre los cuarteles 3 y 4). No obstante debemos aclarar que la zona sur se encuentra subrepresentada, dado que en el recuento faltan los cuarteles 9 y $22 .{ }^{18} \mathrm{En}$ adición detectamos falta de manzanas en 16 de los 38 cuarteles (Dmitruk, 2017).

En la Tabla 3, presentada a continuación, podemos apreciar que la población se aglomeraba en torno a la zona céntrica, donde había actividad económica y administrativa. Entre la zona centro e intermedia, se acumulaba casi el 70\% de la población. En la periferia la concentración era menor, y comenzaban a entremezclarse la actividad comercial y artesanal de las zonas más pobladas con las ocupaciones relacionadas con las actividades agrícolas. En los cuarteles

18 En las planillas censales localizadas en el Archivo General de la Nación Sala X 23-5-5 y 23-5-6 no se encuentran las cédulas correspondientes a ambos cuarteles. Dado que no existió publicación alguna del padrón, es difícil verificar lo sucedido, aunque lo más probables es que las planillas se hayan extraviado a lo largo del tiempo. 
semi rurales o periurbanos observamos un fuerte descenso de la concentración de la población y una presencia creciente de las ocupaciones relacionadas con el sector agropecuario (peones, hortelanos, agricultores, quinteros, acarreadores, hacendados), aunque los oficios artesanales están siempre presentes.

Tabla 3. Distribución espacial de la población según origen. Ciudad de Buenos Aires. 1827. Fuente: Elaboración propia en base a: Archivo General de la Nación: Sala X 23-5-5 y 23-5-6.

\begin{tabular}{lccc}
\hline \multicolumn{1}{c}{ Zona } & Nativos & Inmigrantes & Total \\
& $\%$ & $\%$ & $\%$ \\
\hline Centro & 37,2 & 43,6 & 38,4 \\
Intermedia & 29,8 & 28,7 & 30,6 \\
Periferia & 20,6 & 17,3 & 19,4 \\
Semi rural & 12,4 & 10,4 & 11,6 \\
\hline \multirow{2}{*}{ Total } & 100,0 & 100,0 & 100,0 \\
& $(29726)$ & $(11882)$ & $(41608)$ \\
\hline
\end{tabular}

Sin datos: Nativos: 124 casos. Inmigrantes: 33 casos.

Pensando en esta distribución según las zonas de referencia, veremos si podemos verificar algún tipo de patrón de residencia según las categorías de origen. Ya vimos que la población se concentraba en la zona céntrica e intermedia, por lo que para tener un mejor punto de vista vamos a establecer comparaciones entre nativos e inmigrantes con respecto al total de la población. La distribución de los porteños resultaba similar a la distribución total de la población. Dado que componían más del 70\% de la población de la ciudad, resulta evidente que influían de manera decisiva. La mayor parte de la población porteña se concentraba en la zona centro y disminuía a medida que se alejaba hacia las zonas de la periferia.

Los inmigrantes por su parte, mantenían una tendencia similar, aunque se encontraban sobre representados en la zona céntrica y por el contrario estaban levemente sub representados en el resto.

\section{Estructura socio ocupacional}

Anteriormente mencionamos que el registro sobre las categorías ocupacionales resulta difícil de analizar debido a la escasez de información sobre la mayor parte de la población. En principio observamos una fuerte tendencia a relevar principalmente la ocupación de los jefes de familia masculinos. Por el contrario, en dicha fuente quienes carecen de un oficio relevado son en su mayoría mujeres, lo cual, no quiere decir que no lo tuvieran, sino que el amanuense no lo indagó al momento de realizar el levantamiento. Los varones que no tuvieron oficio relevado eran agregados o familiares del jefe de hogar. Es por eso que pensamos, a modo de hipótesis, que la mayor parte de quienes no cuentan con un oficio registrado en el padrón, pertenecían a los sectores socio laborales subordinados o que en su defecto se encontraban bajo la órbita del jefe de familia dentro del hogar.

En principio elegimos cinco categorías que fueran representativas de esa población no solo en cuanto a la especificidad laboral, sino también en términos socio ocupacionales: 
I) Grandes comerciantes, hacendados, funcionarios (civiles, militares y eclesiásticos) y profesionales;

II) Comerciantes pequeños y medianos;

III) Empleados públicos (civiles y militares), eclesiásticos y privados;

IV) Trabajadores Manuales Calificados (TMC) y labradores;

V) Trabajadores Manuales Calificados aprendices, Trabajadores Manuales No Calificados (TMNC), puesteros y comercio al menudeo, y Trabajadores Rurales. ${ }^{19}$

Para considerar al universo total de la población activa, tomamos en cuenta a la población mayor de 10 años, dado que aparenta haber sido la edad a partir de la cual los censistas comenzaban a registrar la ocupación de la población.

Los autores que trabajaron de manera parcial con el padrón de 1827, resaltan la participación de los Trabajadores Manuales Calificados, los Trabajadores Manuales No Calificados, y también de las ocupaciones comerciales -comerciantes, pulperos, tenderos, abastecedores, etc.- (Andrews, 1989; Di Meglio, 2006: 42; Guzmán, 2012: 10; Dmitruk, 2014b).

En consecuencia, a partir del cruce de las categorías socio ocupacionales con el origen, podemos apreciar que la población inmigrante era más numerosa que la porteña (Tabla 4). A simple vista, puede parecer un dato difícil de entender, dado que los porteños representaban las tres cuartas partes de la población de la ciudad. No obstante, debemos tomar en cuenta que la población nativa estaba conformada en gran medida por niños, que se mantenían por fuera de la actividad laboral, y por mujeres, cuyo oficio el amanuense tendió a no registrar. Como vimos, una parte de los varones nativos en edad activa se encontraba afectada por la leva militar en el ejército de operaciones en la Banda Oriental.

La distribución de porteños e inmigrantes seguía, a grandes rasgos, la tendencia del total de la población: una parte importante se dedicaba al trabajo manual calificado (IV), no calificado (V) y a las actividades comerciales (II, parte de I y parte de V). Si comparamos la representación de ambos grupos con respecto al total, observamos que los porteños presentaban un mayor porcentaje entre las categorías I y III, mientras que entre los inmigrantes se observa una mayor presencia en las categorías II y IV. La sobre representación de los nativos en la categoría III es entendible, dado que incluye la baja burocracia civil, eclesiástica y militar, en su gran mayoría de origen porteño.

19 Teniendo en cuenta que los comerciantes estarían dentro de tres categorías socio ocupacionales (I, II y V), diferenciamos a los grandes comerciantes de sus pares más pequeños a partir de la cantidad de esclavos y de la denominación. En el caso de la denominación general de "comerciante", utilizamos la diferenciación a partir de la mano de obra extrafamiliar (empleados y esclavos) para decidir si incluirlos en la categoría I o en la II. A quienes contaban con un total de mano de obra extrafamiliar de 6 personas o más, los consideramos grandes comerciantes. A su vez tomamos determinadas denominaciones del amanuense para clasificar a los comerciantes dentro de la categoría:

I: abastecedor, negociante, barraquero, dueño de buque, dueño de panadería, dueño de café, fabricante. II: tendero, pulpero, fondero, almacenero.

$\mathrm{V}$ : aguatero, puestero, mercader, mercachifle, repartidor, vendedor.

Los trabajadores manuales calificados eran básicamente artesanos: zapateros, carpinteros, albañiles, barberos, sastres, talabarteros, etc.

Los trabajadores manuales no calificados eran asalariados con escasa o nula calificación: peones, changadores, dependientes, mozos de tienda o de pulpería, etc. 
Mientras que la presencia de los inmigrantes dentro del pequeño y mediano comercio y en el artesanado se debía al peso que tenía la población europea en este sector (Tabla 4).

Tabla 4. Población de 10 años o más con ocupación relevada según categoría socio ocupacional y origen. Ciudad de Buenos Aires, 1827. Fuente: Elaboración propia en base a: Archivo General de la Nación: Sala X 23-5-5 y 23-5-6.

\begin{tabular}{lccc}
\hline $\begin{array}{c}\text { Categoría socio } \\
\text { ocupacional }\end{array}$ & Nativos & Inmigrantes & Total \\
\hline I & 12,3 & 9,2 & 10,7 \\
II & 9,6 & 20,6 & 15,4 \\
III & 9,5 & 3,7 & 6,4 \\
IV & 32,9 & 34,4 & 33,3 \\
V & 35,7 & 32,1 & 34,2 \\
\hline \multirow{2}{*}{ Total } & 100,0 & 100,0 & 100,0 \\
& $(5019)$ & $(5651)$ & $(10682)$ \\
\hline
\end{tabular}

I: Grandes comerciantes, hacendados, funcionarios y profesionales

II: Comerciantes pequeños y medianos

III: Empleados públicos (civiles y militares), eclesiásticos y privados

IV: Trabajadores Manuales Calificados y labradores

V: Trabajadores Manuales Calificados aprendices, Trabajadores Manuales no calificados, puesteros y comercio al menudeo, y Trabajadores Rurales.

Nota: en los totales decidimos incluir a 76 niños menores de 10 años que tienen ocupación declarada.

Sin datos: origen: 16 casos

\section{Años de residencia en la ciudad}

Los años de residencia en la ciudad constituyen una variable muy interesante que ofrece el padrón, dado que permite observar la antigüedad de la inmigración y las diferentes corrientes migratorias. No obstante, debemos tomar con cuidado los datos obtenidos, ya que la variable en cuestión cuenta con una omisión de datos importante. La omisión no se relaciona con una comunidad inmigrante en particular, sino que está relacionada con el subregistro de datos en seis cuarteles en los que las variables están escritas con tinta china, es decir, "a mano”, a diferencia del resto del padrón, confeccionado a partir de planillas impresas. La omisión de esta variable relativa a los años de residencia en estos seis cuarteles (4, 5, 7, 8, 10 y 19) es de $100 \%$, y es por ello que las comunidades inmigrantes que presentan más efectivos en los cuarteles mencionados van a resultar más perjudicadas.

Otra cuestión a considerar es la confiabilidad de los datos registrados, dado que así como una parte importante de la población de la ciudad declaraba su edad de manera errónea (Dmitruk, 2017), debemos considerar que esto mismo podría suceder con la variable "años de residencia".

A raíz de trabajos anteriores en la ciudad de Buenos Aires (Di Meglio, 2006: 64; Dmitruk, 2011: 84) ${ }^{20}$ y en la campaña de Buenos Aires (Mateo, 1993; Mateo, 1999: 166, Santilli, 2000: 333) ${ }^{21}$ pensamos a priori que la población de Buenos Aires

20 Tanto Di Meglio como Dmitruk utilizan dos cuarteles de la ciudad en 1810 y 1827.

21 Mateo y Santilli encuentran un porcentaje importante de migrantes en la campaña (en este caso Lobos y Quilmes) que provendrían tanto de la ciudad de Buenos Aires como de otros pueblos de ocupación más temprana. A su vez Mateo encuentra una gran movilidad incluso dentro del propio Lobos. 
estaba en constante movimiento. No obstante, en otro trabajo encontramos datos que podrían ir en contra de esta afirmación, señalando que la población porteña tendría una movilidad menor a la esperada (Dmitruk, 2014b: 17).

En efecto, nuestros datos parecen reflejar una población inmigrante relativamente estable, con una gran mayoría de inmigrantes asentados desde hacía varios años en la ciudad. De hecho, el porcentaje de inmigrantes que llevaba en la ciudad menos de un año era de 4,6\%.

Como se evidencia en la Tabla 5, presentada a continuación, la distribución porcentual de los años de residencia (Tabla 5) nos indica una particularidad en la distribución de la inmigración, dado que parece haber sido importante hasta los veinte años anteriores al censo; es decir, mientras que ese flujo habría disminuido hacia 1807 -período de las invasiones inglesas y la conflictividad revolucionaria- y vuelto a ser relevante en los cinco años anteriores al censo.

Los datos en cuestión nos revelan la existencia de dos corrientes migratorias bastante definidas, una arribada a la ciudad durante la etapa colonial, y otra que habría llegado a Buenos Aires durante los últimos cinco años anteriores a la confección del censo. A su vez podemos observar que entre 1808 y 1813, en los momentos más álgidos de la conflictividad revolucionaria ${ }^{22}$, se registró el menor número relativo de inmigrantes.

Tabla 5. Población inmigrante con años de residencia registrados. Porcentaje, media y mediana. Ciudad de Buenos Aires. 1827. Fuente: Elaboración propia en base a: Archivo General de la Nación: Sala X 23-5-5 y 23-5-6.

\begin{tabular}{cc}
\hline Años de residencia & Total inmigrantes \\
\hline 0 a 4 & 25,6 \\
5 a 9 & 14,1 \\
10 a 14 & 14,7 \\
15 a 19 & 11,2 \\
20 y más & 34,4 \\
\hline \multirow{2}{*}{ Total } & 100,0 \\
& $(7684)$ \\
\hline Media & \\
Mediana & 15 \\
\end{tabular}

Asimismo, la media y la mediana nos permiten extraer conclusiones similares, la mayor parte de la población inmigrante con años de residencia registrados se encuentra ya asentada en la ciudad desde hace años.

22 Durante el período pos revolucionario se produce la desestructuración de la economía colonial debido a los conflictos bélicos y a la pérdida de los territorios del Alto Perú, Paraguay y la Banda Oriental (al menos desde 1816 por la intervención Luso-Brasileña). Asimismo la propia conflictividad y la pérdida del centro minero de Potosí interrumpe el flujo normal de mercancías, y posiblemente también de las personas (Assadourian y Palomeque, 2014: 48-52) 


\section{Composición de las categorías migratorias}

En esta sección vamos a repetir el diseño de la sección anterior estudiando la estructura, la distribución espacial, las categorías socio ocupacionales y los años de residencia en la ciudad de las distintas categorías migratorias, tomando siempre como punto de comparación al total de los inmigrantes.

\section{África}

\section{Composición interna}

La población africana estaba compuesta por esclavos y libertos, que llegaron a Buenos Aires como inmigrantes forzados. Desde el siglo XVI, el comercio de esclavos fue la solución que encontraron los colonizadores españoles para el problema de la falta de mano de obra en toda América, debido al importante descenso de la población originaria. La región del Río de la Plata no fue la excepción.

En 1827 el porcentaje de esclavos sobre el total de la población africana era de 58\%. El origen de los inmigrantes africanos está representado en el Gráfico 5. Guinea representa el territorio de mayor número relativo, seguido de quienes registraban de manera genérica su origen africano, sin especificación alguna. Observamos también africanos procedentes de antiguas colonias portuguesas: Angola, $\mathrm{Congo}^{23}, \mathrm{Mina}^{24} \mathrm{y}$ Mozambique. De este modo la región de África occidental parece ser la que predominaba, especialmente en las zonas donde Portugal tenía una influencia relevante.

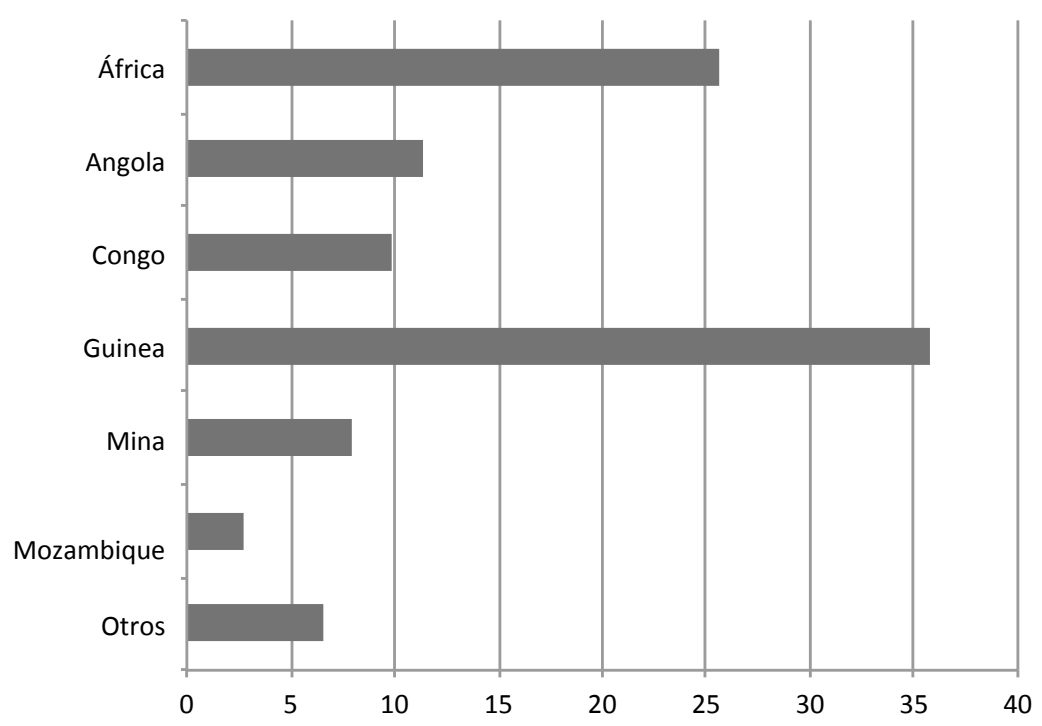

Gráfico 5. Lugares de origen declarados de la población africana. Ciudad de Buenos Aires, 1827 (en porcentaje). Fuente: Elaboración propia en base a: Archivo General de la Nación: Sala $X 23-5-5$ y 23-5-6.

Total: 2.631 casos.

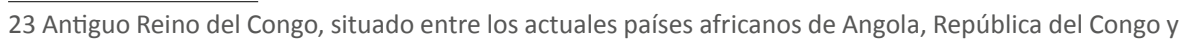
República Democrática del Congo. El Reino del Congo sufrió desde el siglo XV la creciente intromisión del Imperio Portugués, hasta desaparecer hacia fines del siglo XIX.

24 Actual ciudad de Elmina (Ghana), fue durante muchos años un enclave portugués dedicado al comercio de esclavos. 


\section{Estructura de sexo y edad}

Entre los africanos, podemos observar que predominaban levemente las mujeres por sobre los hombres, aunque la distribución de sexos era bastante equilibrada (Tabla 6) y estaba relacionada con la demanda de mano de obra esclava de ambos sexos (las mujeres para realizar trabajos domésticos y los varones llevar a cabo trabajos manuales calificados y no calificados).

Los africanos presentaban una edad media bastante avanzada, debido a que la mayor parte había inmigrado durante la etapa colonial, producto del tráfico de esclavos. No obstante, a partir del auge de ideas libertarias y de las disposiciones de la Asamblea del Año XIII ${ }^{25}$, el comercio de esclavos se fue discontinuando, por lo que la población africana iría envejeciendo de manera progresiva.

Tabla 6. Relación de masculinidad, edad media y edad mediana de la población africana. Ciudad de Buenos Aires, 1827. Fuente: Elaboración propia en base a: Archivo General de la Nación: Sala X 23-5-5 y 23-5-6.

\begin{tabular}{lccc}
\hline Origen & Relación de masculinidad & Edad Media & Edad Mediana \\
\hline África & 93,1 & 39,0 & 38 \\
Total inmigrantes & 163,3 & 35,2 & 32 \\
\hline
\end{tabular}

Total: África: 2.592, sin datos: 39 casos. Total inmigrantes: 11.790 casos, sin datos: 125 casos.

Más allá de la concentración de la población en edades activas, lo cual es razonable en la estructura de una población inmigrante, la pirámide de la población africana presentaba, como datos relevantes, el envejecimiento relativo de la población y la paridad de sexos. Las mujeres tenían una mayor presencia entre los menores de cuarenta años, mientras que los varones contaban con más efectivos entre los adultos mayores, tal como se desprende del Gráfico 6, a continuación.

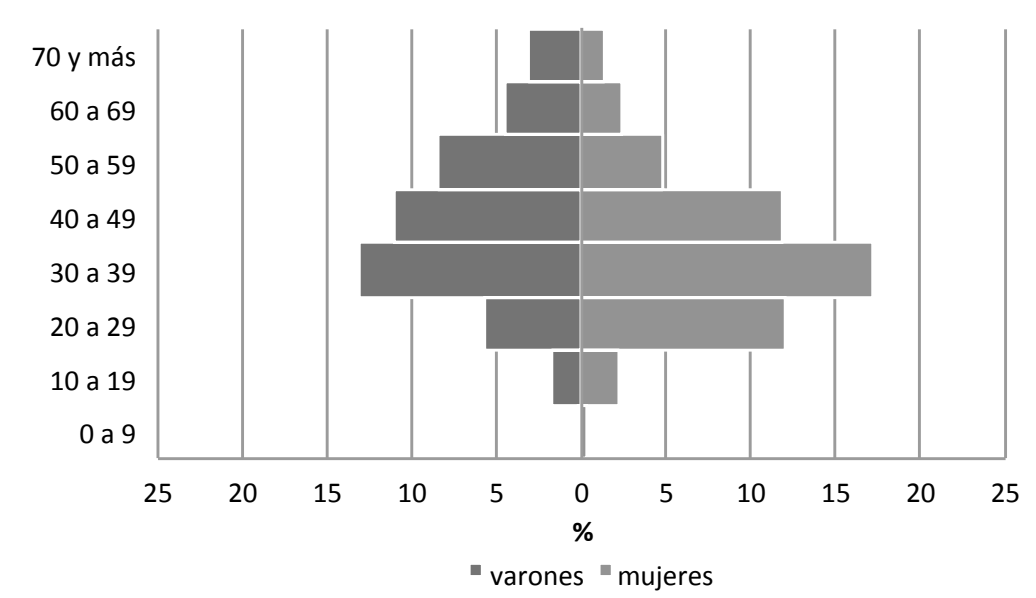

Gráfico 6. Población africana según sexo y edad. Ciudad de Buenos Aires, 1827. Fuente: Elaboración propia en base a Archivo General de la Nación: Sala X 23-5-5 y 23-5-6. Total: 2.592. Sin datos: 39 casos

25 La Asamblea del Año 1813 fue posiblemente el mayor logro del sector radicalizado de la Revolución de Mayo, conformado por los herederos políticos de Mariano Moreno. Si bien la Asamblea no logró declarar la independencia de España, se destacaron algunas medidas de gran avanzada para la época, entre otras: la libertad de vientres (en la práctica concedía la libertad a los hijos de madres esclavas), la libertad de prensa y la prohibición de los títulos nobiliarios y del tributo indígena (Halperin Donghi, 1979: 22-28). 


\section{Distribución espacial}

Al observar la distribución espacial de la población africana en relación al total de inmigrantes, es posible observar que el porcentaje de africanos en la zona céntrica era inferior, mientras que, por el contrario, tenían menos presencia en la zona intermedia. A priori, podríamos pensar que al tratarse de una población en gran parte compuesta por esclavos, vivirían entre los sectores más acomodados de la población, es decir, en la zona céntrica; no obstante, nuestros datos se contraponen con esta presunción. Una posible explicación la encontramos en el peso que tendría el 42\% de población africana libre (que claramente no vivía en la zona céntrica) y en la incidencia que tenían los africanos en el trabajo manual de las zonas alejadas del centro, como puede notarse en Tabla 7.

Tabla 7. Distribución espacial de la población africana y del total de inmigrantes. Ciudad de Buenos Aires, 1827. Fuente: Elaboración propia en base a: Archivo General de la Nación: Sala X 23-5-5 y 23-5-6.

\begin{tabular}{|c|c|c|}
\hline \multirow{2}{*}{ Zona } & África & Total Inmigrantes \\
\hline & $\%$ & $\%$ \\
\hline Centro & 34,3 & 43,6 \\
\hline Intermedia & 35,0 & 28,7 \\
\hline Periferia & 18,9 & 17,3 \\
\hline Semi rural & 11,8 & 10,4 \\
\hline \multirow{2}{*}{ Total } & 100,0 & 100,0 \\
\hline & (2.622) & (11.882) \\
\hline
\end{tabular}

Sin datos: África: 9 casos. Total inmigrantes: 33 casos.

\section{Estructura socio ocupacional}

Entre la población africana con oficio registrado, podemos apreciar una subrepresentación en todas las categorías de ocupaciones no manuales y, por el contrario, un porcentaje elevado entre los oficios manuales tanto calificados ${ }^{26}$ como no calificados, oficios en los que se especializaban siendo esclavos o ex esclavos. Por otra parte, nos resulta evidente que su actividad económica era ciertamente invisibilizada por el censo, dado que componían el 22\% de la población inmigrante y apenas el 9\% de los inmigrantes con ocupación registrada (Tabla 8). En este sentido parecían sufrir un doble estigma, por un lado, relacionado con el color de piel $^{27}$ y, por otro, por tratarse de trabajadores manuales, los cuales sin dudas eran más vulnerables a los caprichos del mercado de trabajo.

26 Una de las opciones de inversión de la época se trataba de comprar un esclavo, enseñarle un oficio artesanal y de este modo quedarse con parte de las ganancias obtenidas (Goldberg, 1976: 88). Suponemos que a partir de 1810 con el auge de las ideas libertarias esta costumbre disminuyó aunque para 1827 contamos todavía con 247 esclavos que ofician como trabajadores manuales calificados. 
Tabla 8. Población africana y total de inmigrantes de 10 años o más con ocupación relevada según categoría socio ocupacional. Ciudad de Buenos Aires, 1827. Fuente: Elaboración propia en base a: Archivo General de la Nación: Sala X 23-5-5 y 23-5-6.

\begin{tabular}{lcc}
\hline Categoría socio ocupacional & África & Total Inmigrantes \\
\hline I & 0,9 & 9,2 \\
II & 1,4 & 20,6 \\
III & 1,3 & 3,7 \\
IV & 46,9 & 34,4 \\
V & 49,5 & 32,1 \\
\hline \multirow{2}{*}{ Total } & 100,0 & 100,0 \\
& $(556)$ & $(5.651)$ \\
\hline
\end{tabular}

I: Grandes comerciantes, hacendados, funcionarios y profesionales

II: Comerciantes pequeños y medianos

III: Empleados públicos (civiles y militares), eclesiásticos y privados

IV: Trabajadores Manuales Calificados y labradores

V: Trabajadores Manuales Calificados aprendices, Trabajadores Manuales no calificados, puesteros y comercio al menudeo, y Trabajadores Rurales.

Nota: en el total de inmigrantes decidimos incluir a 10 niños menores de 10 años que tienen ocupación declarada.

\section{Años de residencia en la ciudad}

Los africanos eran el grupo migratorio que más años en promedio tenía residiendo en la ciudad. A su vez, también observamos que la mayoría de los africanos con años de residencia registrados, hacía más de 20 años que estaban en la ciudad. Por el contrario, el porcentaje se reduce a medida que nos acercamos a la fecha del censo, al punto de que apenas algo más del 2\% de los africanos había arribado a la ciudad en los últimos 5 años. La inmigración africana era, sin dudas, producto de la herencia del comercio de esclavos. A partir de las nuevas ideas libertarias -tanto en el Río de la Plata como en el mundo en general-, y de las restricciones que empezó a sufrir el comercio negrero, la llegada de esclavos africanos se hizo cada vez más compleja (Tabla 9).

Tabla 9. Población africana y total de inmigrantes con años de residencia registrados. Porcentaje, media y mediana. Ciudad de Buenos Aires, 1827. Fuente: Elaboración propia en base a: Archivo General de la Nación: Sala X 23-5-5 y 23-5-6.

\begin{tabular}{lcc}
\hline Años de residencia & África & Total inmigrantes \\
\hline 0 a 4 & 2,2 & 25,6 \\
5 a 9 & 3,0 & 14,1 \\
10 a 14 & 12,7 & 14,7 \\
15 a 19 & 20,4 & 11,2 \\
20 y más & 61,7 & 34,4 \\
\hline \multirow{2}{*}{ Total } & 100,0 & 100,0 \\
& $(1.718)$ & $(7.684)$ \\
\hline Media & & \\
Mediana & 22,2 & 15 \\
\hline
\end{tabular}

\section{Europa}

\section{Composición interna}

Al momento de observar el origen de la población europea en la ciudad de Buenos Aires, decidimos separar a la población de origen español del resto de Europa. Debido al peso propio, tanto en volumen como en relevancia socio económica, y 
tratándose de los antiguos conquistadores, creemos que la población española debe ser estudiada aparte, por lo que en esta sección solo nos dedicaremos a la población europea, dejando de lado a los españoles.

La ciudad de Buenos Aires recibió, desde sus orígenes, inmigración europea. No obstante, a partir de la Revolución de Mayo en 1810 la población proveniente de Europa aumentó de manera considerable y se fue diversificando (Massé,1992: 174; Dmitruk, 2011). En este sentido, el fin del monopolio comercial $^{28}$, la apertura económica con Inglaterra como nueva metrópoli y la existencia de una legislación más abierta hacia los extranjeros, contribuyeron a la llegada de europeos de distintos países.

En el Gráfico 7, que se presenta a continuación, puede notarse que Inglaterra y Francia eran los orígenes más frecuentes entre los inmigrantes. Más aún, la afluencia de ingleses (y británicos en general) se hizo más notoria debido al tratado firmado en 1825, que favoreció la radicación de artesanos y hombres de negocios ${ }^{29}$.

Con un porcentaje menor aparecen portugueses e italianos. La inmigración portuguesa tuvo larga tradición en la ciudad de Buenos Aires, aunque nunca logró un peso cuantitativo demasiado relevante. La inmigración italiana, por su parte, estuvo relacionada con las actividades portuarias y fue creciendo luego de la independencia. Otros orígenes revisten alguna relevancia: Alemania, y también Escocia e Irlanda, beneficiarios del citado tratado con el Reino Unido.

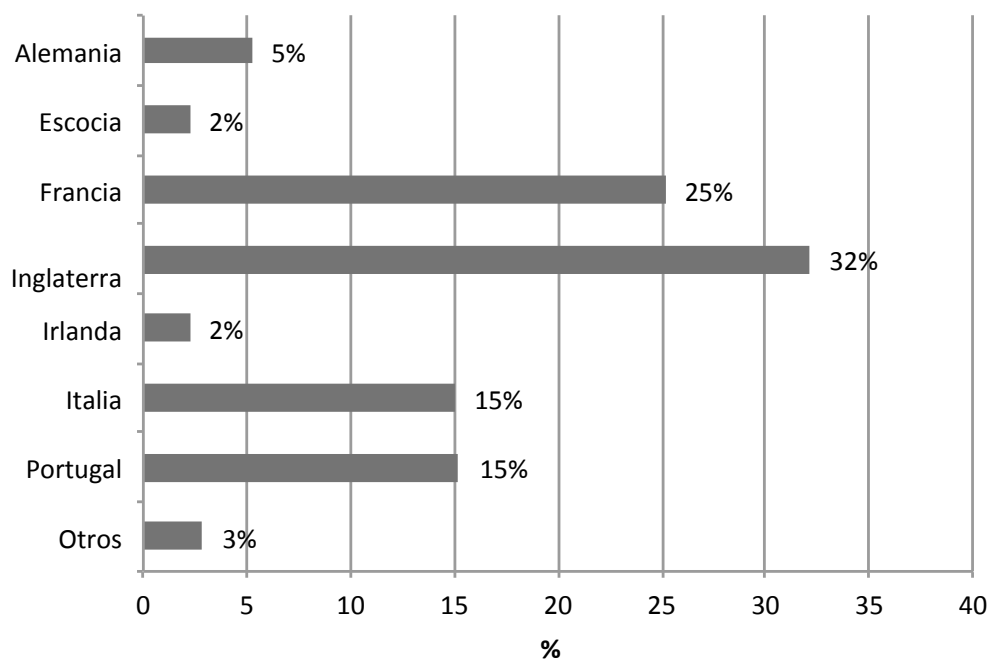

Gráfico 7. Composición de la población europea. Ciudad de Buenos Aires, 1827 (en porcentaje). Fuente: Elaboración propia en base a: Archivo General de la Nación: Sala X 23-5-5 y 23-5-6. Total: 2.336 casos.

28 El monopolio comercial suponía que las colonias españolas podían comerciar únicamente con la metrópoli. Durante las reformas borbónicas el comercio se amplió también a determinados puertos autorizados de los territorios coloniales. De más está decir que un reglamento tan restrictivo incentivaba el contrabando comercial, sin el cual la ciudad de Buenos Aires no podía abastecerse de manera adecuada (Brown, 2002: 33-38).

29 En 1825 se firmó un tratado entre el Reino Unido y Las Provincias Unidas del Río de la Plata. Si bien no llegó a reconocer la independencia de España, el tratado de "amistad, comercio y navegación", favorecería la instalación de súbditos británicos, a los cuales veremos asentados en la ciudad de Buenos Aires particularmente como artesanos y comerciantes (Tratado de Amistad, Comercio y Navegación celebrado entre las Provincias Unidas del Río de la Plata y Su Majestad Británica (1825)). 


\section{Estructura de sexo y edad}

En lo que respecta a la tasa de masculinidad, los europeos presentan una distribución de sexos ciertamente desequilibrada, de más de seiscientos varones por cada cien mujeres. Evidentemente eran más propensos a migrar solos o con un grupo de paisanos. A su vez, la edad media y la edad mediana tienden a ser algo menores que la observada en el total de la población inmigrante.

Tabla 10. Relación de masculinidad, edad media y edad mediana de la población europea y el total de inmigrantes. Ciudad de Buenos Aires, 1827. Fuente: Elaboración propia en base a: Archivo General de la Nación: Sala X 23-5-5 y 23-5-6.

\begin{tabular}{lccc}
\hline Origen & $\begin{array}{c}\text { Relación de } \\
\text { masculinidad }\end{array}$ & Edad Media & Edad Mediana \\
\hline Europa & 431,5 & 31,1 & 30 \\
Total inmigrantes & 163,3 & 35,2 & 32 \\
\hline
\end{tabular}

Total: Europa: 2.329 casos, sin datos: 7 casos. Total inmigrantes: 11.790 casos, sin datos: 125 casos.

Por su parte, la pirámide de población que se expone en el Gráfico 8 nos permite observar el fuerte desequilibrio de los sexos en favor de los efectivos masculinos. Podemos apreciar también la concentración de la población entre los 20 y los 40 años, mientras que la ausencia de mujeres y niños nos permite reafirmar nuestra idea que la inmigración europea estaba compuesta prácticamente en su totalidad por hombres solos.

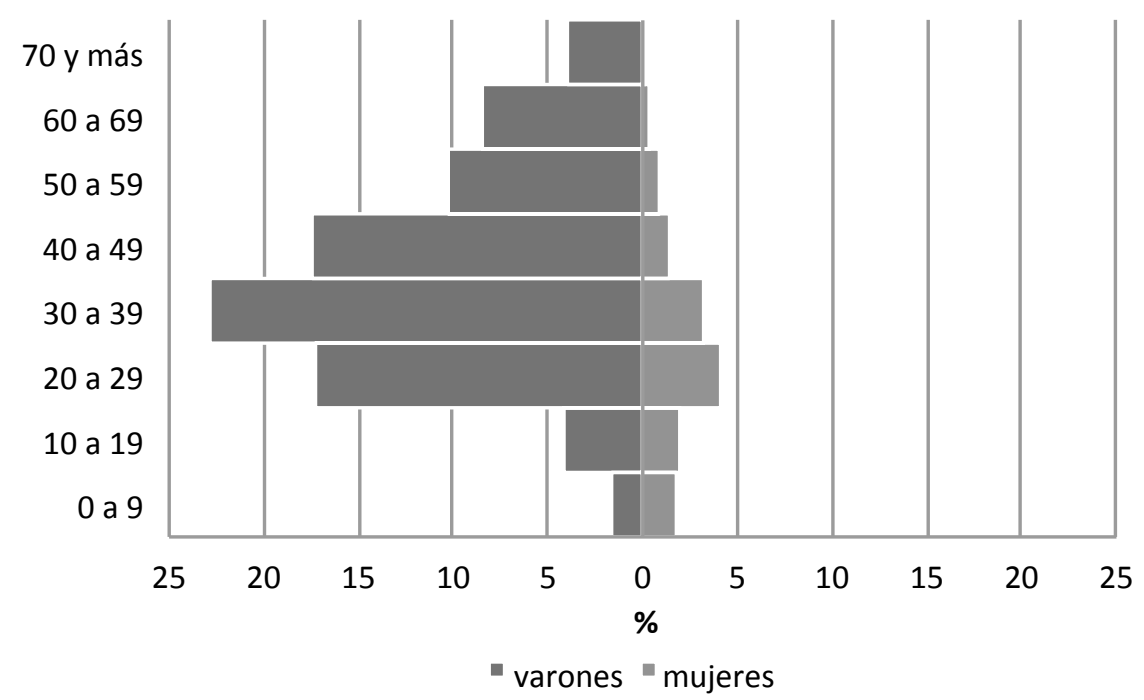

Gráfico 8. Población Europea según sexo y edad. Ciudad de Buenos Aires, 1827. Fuente: Elaboración propia en base a: Archivo General de la Nación: Sala X 23-5-5 y 23-5-6. Total: 2.320 casos. Sin datos: 16 casos.

\section{Distribución espacial}

La Tabla 11, presentada a continuación, muestra que la distribución de la población europea se concentraba fuertemente en la zona céntrica, donde se encontraba el poder económico y administrativo de la ciudad. Por el contrario, el porcentaje de europeos era ciertamente menor en las zonas alejadas del centro. 
Tabla 11. Distribución espacial de la población europea y el total de inmigrantes. Ciudad de Buenos Aires. 1827. Fuente: Elaboración propia en base a: Archivo General de la Nación: Sala X 23-5-5 y 23-5-6.

\begin{tabular}{lcc}
\hline Zona & Europa & Total Inmigrantes \\
& $\%$ & $\%$ \\
\hline Centro & 64,3 & 43,6 \\
Intermedia & 20,8 & 28,7 \\
Periferia & 8,8 & 17,3 \\
Semi rural & 6,1 & 10,4 \\
\hline Total & 100,0 & 100,0 \\
& $(2331)$ & $(11882)$ \\
\hline
\end{tabular}

Sin datos: Europa: 5 casos. Total inmigrantes: 33 casos.

\section{Estructura socio ocupacional}

La Tabla 12 muestra que los europeos presentaban una mayor representación que el total de los inmigrantes entre el pequeño y mediano comercio, pero también entre los trabajadores manuales calificados. En cambio su representación era menor entre los oficios no calificados.

Mucho se ha hablado acerca de que a partir de la independencia y el fin del monopolio español sobre el comercio, los comerciantes europeos, particularmente británicos, se convirtieron en la nueva élite de la ciudad de Buenos Aires post colonial (Halperin Donghi, 1979). De todos modos, también debemos remarcar la importancia de la población europea entre los trabajadores manuales calificados, al punto de que parecen haber desplazado a sus pares porteños y españoles. Así, podemos afirmar que no solo llegaban comerciantes del viejo continente, sino también gentes de oficio en busca de mejores oportunidades.

Tabla 12. Población europea y total de inmigrantes de 10 años o más con ocupación relevada según categoría socio ocupacional. Ciudad de Buenos Aires, 1827. Fuente: Elaboración propia en base a: Archivo General de la Nación: Sala X 23-5-5 y 23-5-6.

\begin{tabular}{lcc}
\hline Categoría socio ocupacional & Europa & Total Inmigrantes \\
\hline I & 8,9 & 9,2 \\
II & 24,8 & 20,6 \\
III & 2,2 & 3,7 \\
IV & 43,7 & 34,4 \\
V & 20,4 & 32,1 \\
\hline \multirow{2}{*}{ Total } & 100,0 & 100,0 \\
& $(1.658)$ & $(5.651)$ \\
\hline
\end{tabular}

I: Grandes comerciantes, hacendados, funcionarios y profesionales

II: Comerciantes pequeños y medianos

III: Empleados públicos (civiles y militares), eclesiásticos y privados

IV: Trabajadores Manuales Calificados y labradores

V: Trabajadores Manuales Calificados aprendices, Trabajadores Manuales no calificados, puesteros y comercio al menudeo, y Trabajadores Rurales.

Nota: en el total de inmigrantes decidimos incluir a 10 niños menores de 10 años que tienen ocupación declarada y en el total de Europa incluimos a 4 niños menores de 10 años con ocupación declarada.

\section{Años de residencia en la ciudad}

En 1827, la población europea en la ciudad de Buenos Aires estaba compuesta por una inmigración más bien reciente, dado que más de la mitad de quienes 
registraban la variable "años de residencia" habían llegado a la ciudad en los últimos cinco años. Una gran parte de los europeos eran súbditos británicos, beneficiados por el mencionado tratado entre el Reino Unido y las Provincias Unidas. Los datos que ofrecen los valores de la media y la mediana van en la misma dirección, la inmigración europea era más reciente que la del total de los inmigrantes, tal como se desprende de la Tabla 13. A su vez podríamos trazar diferentes etapas según la nacionalidad en cuestión. Los súbditos británicos, franceses y alemanes habían inmigrado en años recientes al censo, mientras que, por el contrario, italianos y portugueses presentaban una inmigración más antigua, que incluso se remontaba a la etapa colonial.

Tabla 13. Población europea y total de inmigrantes con años de residencia registrados. Porcentaje, media y mediana. Ciudad de Buenos Aires. 1827. Fuente: Elaboración propia en base a: Archivo General de la Nación: Sala X 23-5-5 y 23-5-6.

\begin{tabular}{lcc}
\hline Años de residencia & Europa & Total inmigrantes \\
\hline 0 a 4 & 54,6 & 25,6 \\
5 a 9 & 21,9 & 14,1 \\
10 a 14 & 9,7 & 14,7 \\
15 a 19 & 3,8 & 11,2 \\
20 y más & 10,0 & 34,4 \\
\hline \multirow{2}{*}{ Total } & 100,0 & 100,0 \\
& $(1.524)$ & $(7.684)$ \\
\hline Media & & \\
Mediana & 7 & 15 \\
\hline
\end{tabular}

\section{España}

\section{Composición interna}

Como mencionamos anteriormente, los españoles concentraban casi la mitad de la población europea en la ciudad de Buenos Aires; es por eso que decidimos llevar a cabo el análisis de esta subcategoría de manera diferenciada del resto de los europeos.

En principio, debemos mencionar que para 1827 la presencia española seguía siendo importante, aún a pesar del clima antipeninsular posterior a 1810. Incluso tenemos la firme sospecha de que una gran parte de la población que declaraba haber nacido en "Europa" era también de origen español, ya que hemos podido apreciar entre que quienes declaraban ser "europeos" de manera genérica, sin una nacionalidad en particular, llevaban apellidos de origen español y tenían una estructura socio demográfica bastante similar a los que declaraban ser "españoles" en sexo y edad, edad media y categoría socio ocupacional.

Entre la población española contamos un porcentaje importante que registraba su origen de manera genérica como "España", de modo que no podemos obtener un registro de su patria chica. Entre las comunidades españoles observamos una participación relevante de Galicia y Andalucía, dos regiones portuarias de algún modo emparentadas con el comercio atlántico, al igual que Buenos Aires. Los catalanes y los vascos, les seguían con un porcentaje menor, tal como indica el siguiente gráfico. 


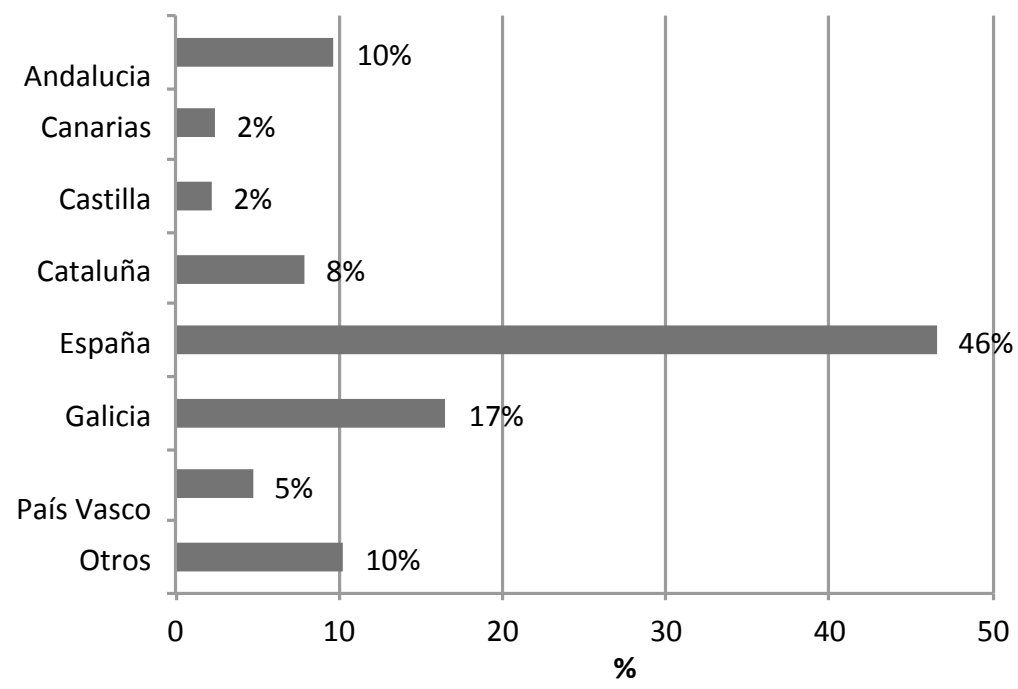

Gráfico 9. Composición de la población española. Ciudad de Buenos Aires, 1827 (en porcentaje). Fuente: Elaboración propia en base a: Archivo General de la Nación: Sala X 23-5-5 y 23-5-6. Total: 1.517 casos, sin datos: 258 casos.

\section{Estructura de sexo y edad}

Los españoles presentaban una población fuertemente desequilibrada en favor de los varones. La relación de masculinidad superaba los mil varones por cada cien mujeres. También se trataba de una población envejecida, con un promedio de edad elevado. Existía una fuerte concentración en los varones mayores de 30 años, e incluso se evidencia un importante número relativo de adultos mayores. Al igual que lo observado con el resto de la población europea, podemos vislumbrar una inmigración compuesta por hombres solos, a juzgar por el escaso número de niños y mujeres (Tabla 14 y Gráfico 10).

Tabla 14. Relación de masculinidad, edad media y edad mediana de la población española y el total de inmigrantes. Ciudad de Buenos Aires. 1827. Fuente: Elaboración propia en base a: Archivo General de la Nación: Sala X 23-5-5 y 23-5-6.

\begin{tabular}{lccc}
\hline Origen & $\begin{array}{c}\text { Relación de } \\
\text { masculinidad }\end{array}$ & Edad media & Edad Mediana \\
\hline España & 1174,8 & 46,6 & 46 \\
Total inmigrantes & 163,3 & 35,2 & 32 \\
\hline
\end{tabular}

Total: España: 1.770 casos, sin datos: 4 casos. Total inmigrantes: 11.790 casos, sin datos: 125 casos. 


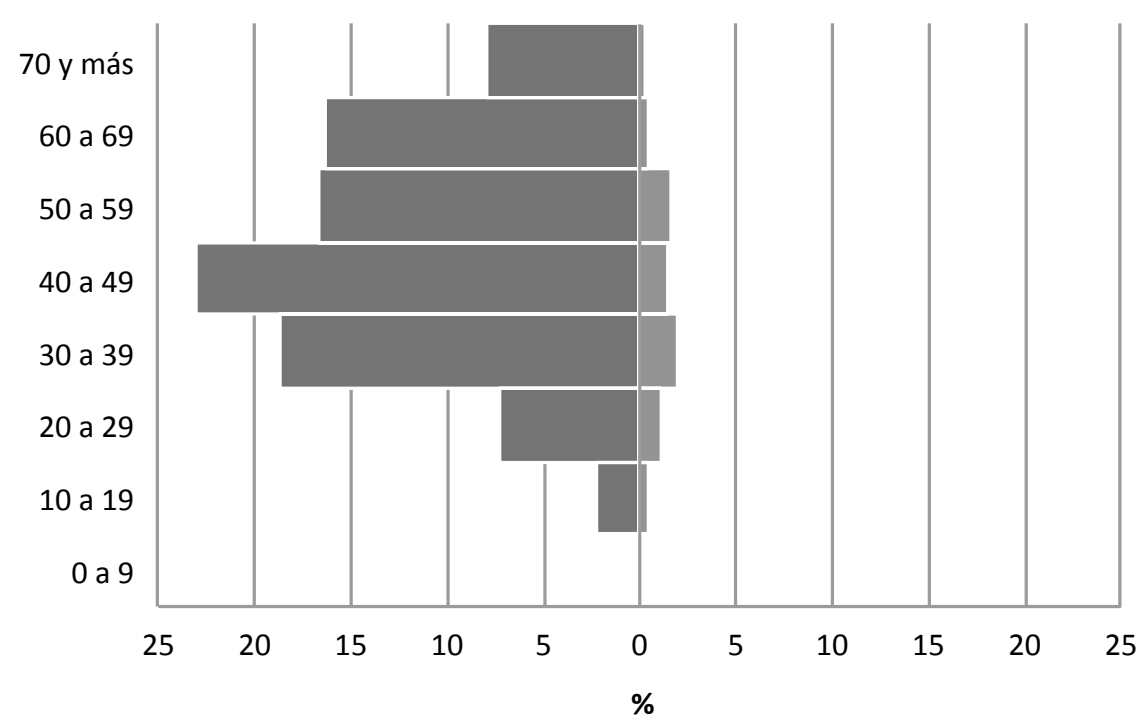

Gráfico 10. Población española según sexo y edad. Ciudad de Buenos Aires, 1827. Fuente: Elaboración propia en base a: Archivo General de la Nación: Sala X 23-5-5 y 23-5-6. Total: 1.770 casos, sin datos: 4 casos.

\section{Distribución espacial}

La distribución de los españoles según la zona residencial se asemejaba a la que presentaba el total de los inmigrantes, no obstante era algo más elevada en el centro de la ciudad, donde vivía casi la mitad de los españoles, producto de su vinculación con la economía atlántica. En la las áreas periféricas, por el contrario, su número relativo era bastante menor, como lo evidencia la Tabla 15.

Tabla 15. Distribución espacial de la población española y el total de inmigrantes. Ciudad de Buenos Aires, 1827. Fuente: Elaboración propia en base a: Archivo General de la Nación: Sala X 23-5-5 y 23-5-6.

\begin{tabular}{lcc}
\hline \multirow{2}{*}{ Zona } & España & Total Inmigrantes \\
& $\%$ & $\%$ \\
\hline Centro & 48,5 & 43,6 \\
Intermedia & 30,3 & 28,7 \\
Periferia & 13,8 & 17,3 \\
Semi rural & 7,4 & 10,4 \\
\hline \multirow{2}{*}{ Total } & 100,0 & 100,0 \\
& $(1.769)$ & $(11.882)$ \\
\hline
\end{tabular}

Sin datos: España: 5 casos, total inmigrantes: 33 casos.

\section{Estructura socio ocupacional}

Al comparar la estructura socio ocupacional de los españoles con el total de inmigrantes, podemos observar que los primeros contaban con un mayor número relativo en las dos categorías principales (I y II). Por el contrario, tenían un menor porcentaje en las categorías relacionadas con el trabajo manual. Más allá del ya citado clima antipeninsular posterior a la Revolución de Mayo, continuaban siendo, debido a la herencia colonial, un actor de gran relevancia en la economía 
porteña, e incluso más de la mitad de los españoles que registraron ocupación se encontraban en las dos principales categorías socio ocupacionales (Tabla 16).

Tabla 16. Población española y total de inmigrantes de 10 años o más con ocupación relevada según categoría socio ocupacional. Ciudad de Buenos Aires. 1827. Fuente: Elaboración propia en base a: Archivo General de la Nación: Sala X 23-5-5 y 23-5-6.

\begin{tabular}{lcc}
\hline Categoría socio ocupacional & España & Total Inmigrantes \\
\hline I & 14,8 & 9,2 \\
II & 39,0 & 20,6 \\
III & 3,6 & 3,7 \\
IV & 22,5 & 34,4 \\
V & 20,1 & 32,1 \\
\hline \multirow{2}{*}{ Total } & 100,0 & 100,0 \\
& $(1.363)$ & $(5.651)$ \\
\hline
\end{tabular}

I: Grandes comerciantes, hacendados, funcionarios y profesionales

II: Comerciantes pequeños y medianos

III: Empleados públicos (civiles y militares), eclesiásticos y privados

IV: Trabajadores Manuales Calificados y labradores

V: Trabajadores Manuales Calificados aprendices, Trabajadores Manuales no calificados, puesteros y comercio al menudeo, y Trabajadores Rurales.

Nota: en el total de inmigrantes decidimos incluir a 10 niños menores de 10 años que tienen ocupación declarada y en el total de España incluimos a 1 niño menor de 10 años con ocupación declarada.

\section{Años de residencia en la ciudad}

La población española en la ciudad de Buenos Aires presentaba una inmigración más antigua, comparada con el total de inmigrantes. El cálculo de la mediana y la media nos permiten observar una inmigración que alcanzaba y superaba los veinte años, es decir, que se remontaba a la época colonial. La distribución porcentual nos revela, en el mismo sentido, que la mayor parte de los españoles con años de residencia registrados había arribado a la ciudad antes de la Revolución de Mayo. La llegada de los españoles durante la etapa colonial tuvo que ver con la posición social de privilegio que disfrutaban, fundamentalmente debido al monopolio comercial y la distribución de cargos públicos. Si bien está claro que el flujo migratorio se redujo drásticamente con la Revolución de Mayo, a partir de allí se mantuvo estable en el orden del 11\% (Tabla 17).

Tabla 17. Población española y total de inmigrantes con años de residencia registrados. Porcentaje, media y mediana. Ciudad de Buenos Aires. 1827. Fuente: Elaboración propia en base a: Archivo General de la Nación: Sala X 23-5-5 y 23-5-6.

\begin{tabular}{lcc}
\hline Años de residencia & España & Total inmigrantes \\
\hline 0 a 4 & 11,4 & 25,6 \\
5 a 9 & 9,0 & 14,1 \\
10 a 14 & 11,6 & 14,7 \\
15 a 19 & 11,9 & 11,2 \\
20 y más & 56,1 & 34,4 \\
\hline Total & 100,0 & 100,0 \\
& $(1.015)$ & $(7.684)$ \\
\hline Media & & 15 \\
Mediana & 22,9 & 13 \\
\hline
\end{tabular}




\section{Migrantes internos}

\section{Composición interna}

La ciudad de Buenos Aires fue, desde el siglo XVIII, un foco de atracción de población debido a la expansión económica generada por el puerto, lo que implicó una demanda constante de trabajadores en todos los sectores de la economía. Los inmigrantes internos conformaron una parte importante de la mano de obra de la ciudad (Díaz, 1997 y 1998; 2003).

La inmigración interna tiene un cariz definitivamente distinto a la inmigración externa. Tanto por la cercanía geográfica, como por afinidad cultural, se trata de una inmigración diferente, que en muchos casos se dio por etapas desde el norte, e incluso algunos de ellos solo estarían de paso en la ciudad de camino hacia la frontera de la campaña bonaerense (Mateo, 1993: 134; Santilli, 2000: 337).

En este plano, se destacan en primer lugar los cordobeses como una primera minoría (Gráfico 11). Santafesinos, tucumanos, mendocinos y santiagueños les seguían, aunque con un peso relativo bastante menor. Por último se destacaban los correntinos, sanjuaninos y bonaerenses, provenientes del interior de la Provincia de Buenos Aires. Las zonas centro (Córdoba, Santiago del Estero y Provincia de Buenos Aires) y el litoral (Santa Fe, Corrientes y Entre Ríos) eran las que mayor inmigración aportaban a la ciudad; en cierto modo es lógico, dado que eran las más cercanas, además en un período donde el transporte era lento y dificultoso, desde el litoral se podía acceder fácilmente navegando a través de la cuenca de los ríos Paraná-de la Plata. ${ }^{30}$

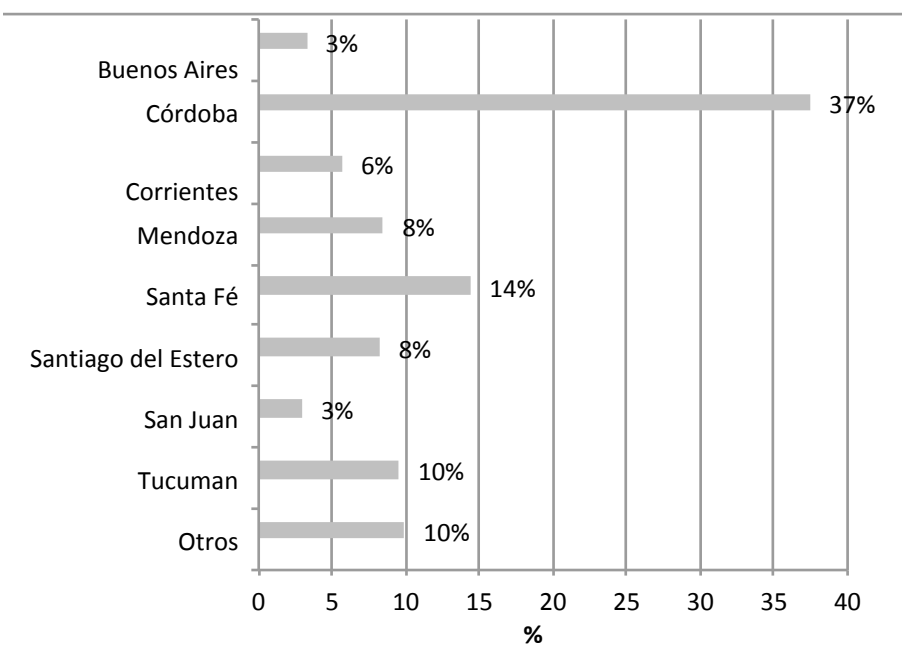

Gráfico 11. Composición de la población nacida en el interior. Ciudad de Buenos Aires. 1827. Fuente: Elaboración propia en base a: Archivo General de la Nación: Sala X 23-5-5 y 23-5-6. Total: 3.276 casos, sin datos: 27 casos.

30 Desde el siglo XVIII se produce una corriente migratoria dentro del Virreinato del Río de la Plata con dirección norte-sur, hacia la ciudad y la campaña de Buenos Aires, en busca de tierras disponibles (en la campaña) y mejores oportunidades laborales (en la ciudad), por cuestiones de cercanía la campaña norte y los alrededores de la Ciudad son los primeros territorios en recibir a los inmigrantes, mientras que ya a principios del siglo XIX la campaña norte y la ciudad ya no ofrecen tantas oportunidades por lo que la inmigración se vuelca hacia el sur. Existe una extensa bibliografía desarrollada durante la década de 1990 que documenta estos movimientos (entre otros: Farberman, 1992; Garavaglia y Moreno, 1993; Díaz, 1997 y 1998; Gelman, 1998; Garavaglia, 1999; Fradkin, Canedo y Mateo, 1999; Santilli, 2000). 


\section{Estructura de sexo y edad}

La distribución de sexo y edad de los inmigrantes internos nos revela una población bastante equilibrada, aunque se manifiesta cierta preponderancia de las mujeres por sobre los varones. A su vez, observamos una población algo más rejuvenecida. La pirámide de población nos permite apreciar la presencia de niños y un relativo equilibrio entre los sexos, lo que nos da la pauta de la existencia de una corriente migratoria que implicaba a toda la familia, y no solo a los varones (Tabla $18 \mathrm{y}$ Gráfico 12). El leve desequilibrio entre los sexos a favor de las mujeres, se observa básicamente entre los 10 y los 39 años, lo cual podría tener que ver la afluencia de mano de obra femenina a la ciudad que se ocupaba en las tareas relacionadas con el trabajo doméstico (lavanderas, costureras, planchadoras, sirvientas) o con oficios semicalificados (como el caso de las cigarreras). De hecho, hemos podido comprobar que las mujeres provenientes del interior de las Provincias Unidas componían el principal grupo inmigrante femenino con ocupación relevada.

Tabla 18. Relación de masculinidad, edad media y edad mediana de la población nacida en el interior y el total de inmigrantes. Ciudad de Buenos Aires, 1827. Fuente: Elaboración propia en base a: Archivo General de la Nación: Sala X 23-5-5 y 23-5-6.

\begin{tabular}{lccc}
\hline \multicolumn{1}{c}{ Origen } & $\begin{array}{c}\text { Relación de } \\
\text { masculinidad }\end{array}$ & Edad Media & Edad Mediana \\
\hline Interior & 86,3 & 30,4 & 30 \\
Total inmigrantes & 163,3 & 35,2 & 32 \\
\hline
\end{tabular}

Total: Interior: 3.254 casos, sin datos: 49 casos. Total inmigrantes: 11.790 casos, sin datos: 125 casos.

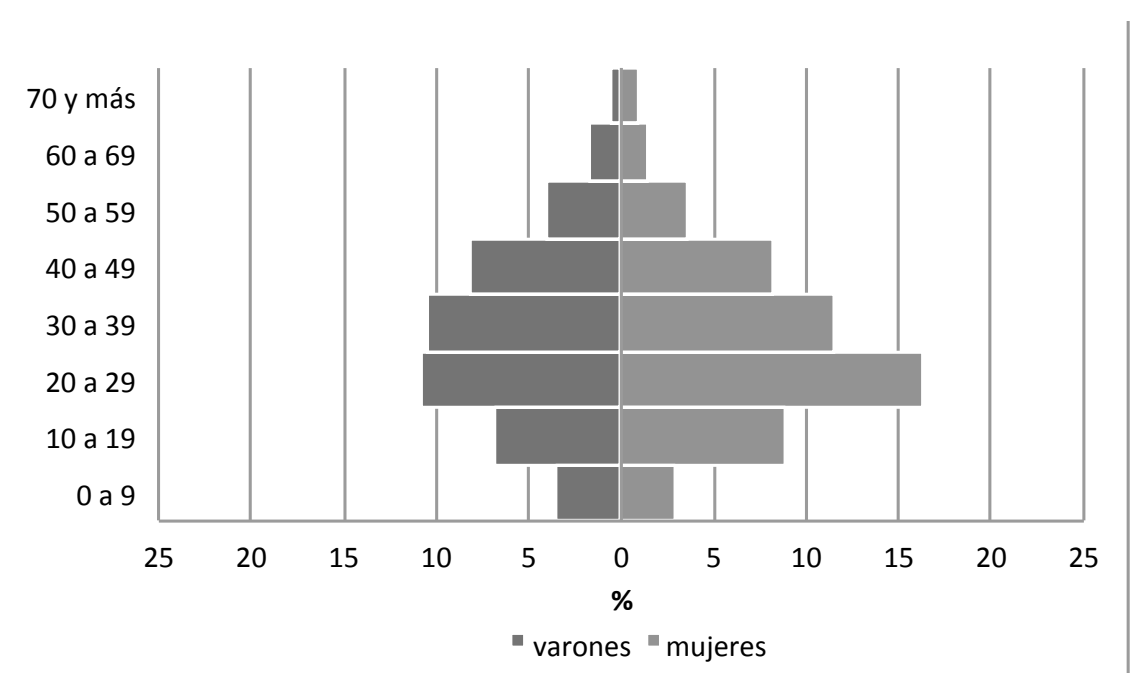

Gráfico 12. Población nacida en el interior según sexo y edad. Ciudad de Buenos Aires, 1827. Fuente: Elaboración propia en base a: Archivo General de la Nación: Sala X 23-5-5 y 23-5-6. Total: 3.254 casos, sin datos: 49 casos.

\section{Distribución espacial}

Si bien la distribución espacial de la población de inmigrantes internos seguía una tendencia similar al total de inmigrantes (es decir, presentaba porcentajes decrecientes desde el centro a las áreas más alejadas), en comparación su número relativo era más reducido en la zona centro, y superior al total de inmigrantes en las zonas más alejadas (Tabla 19). 
Tabla 19. Distribución espacial de la población nacida en el interior y del total de inmigrantes. Ciudad de Buenos Aires. 1827. Fuente: Elaboración propia en base a: Archivo General de la Nación: Sala X 23-5-5 y 23-5-6.

\begin{tabular}{lcc}
\hline Zona & Interior & Total Inmigrantes \\
& $\%$ & $\%$ \\
\hline Centro & 34,8 & 43,6 \\
Intermedia & 27,4 & 28,7 \\
Periferia & 23,6 & 17,3 \\
Semi rural & 14,2 & 10,4 \\
\hline Total & 100,0 & 100,0 \\
& $(3.291)$ & $(11.882)$ \\
\hline
\end{tabular}

Sin datos: Interior: 12 casos, total inmigrantes: 33 casos.

\section{Estructura socio ocupacional}

Los inmigrantes internos contaban con una mayor representación entre los oficios de menor calificación, por lo cual podemos inferir su pertenencia a los sectores más pobres de la sociedad porteña. Observamos también una presencia importante entre el trabajo manual calificado, aunque en este caso se encontraban sub representados con respecto al total de los inmigrantes. A su vez el porcentaje de inmigrantes internos entre las dos principales categorías socio ocupacionales (I y II) era relativamente bajo, especialmente entre los pequeños y medianos comerciantes (Tabla 10).

Tabla 20. Población nacida en el interior y total de inmigrantes de 10 años o más con ocupación relevada según categoría socio ocupacional. Ciudad de Buenos Aires. 1827. Fuente: Elaboración propia en base a: Archivo General de la Nación: Sala X 23-5-5 y 23-5-6.

\begin{tabular}{lcc}
\hline Categoría socio ocupacional & Interior & Total Inmigrantes \\
\hline I & 8,1 & 9,2 \\
II & 8,3 & 20,6 \\
III & 4,6 & 3,7 \\
IV & 30,5 & 34,4 \\
V & 48,5 & 32,1 \\
\hline \multirow{2}{*}{ Total } & 100,0 & 100,0 \\
& $(1.251)$ & $(5.651)$ \\
\hline
\end{tabular}

I: Grandes comerciantes, hacendados, funcionarios y profesionales

II: Comerciantes pequeños y medianos

III: Empleados públicos (civiles y militares), eclesiásticos y privados

IV: Trabajadores Manuales Calificados y labradores

V: Trabajadores Manuales Calificados aprendices, Trabajadores Manuales no calificados, puesteros y comercio al menudeo, y Trabajadores Rurales.

Nota: en el total de inmigrantes decidimos incluir a 10 niños menores de 10 años que tienen ocupación declarada y en el total de inmigrantes incluimos a 4 niños menores de 10 años con ocupación declarada.

\section{Años de residencia en la ciudad}

Entre los inmigrantes internos, parecía haber una corriente migratoria relevante durante la época colonial, que se cortaría de manera abrupta durante la etapa revolucionaria. Pasados los primeros años de la década de 1810, esta corriente se reactivaría y aumentaría de manera marcada a partir de 1813 y especialmente en los cinco años anteriores a la confección del padrón de 1827 (Tabla 21). En cierto modo la conflictividad bélica derivada de la Revolución de Mayo pareció afectar en gran medida a la afluencia de inmigrantes internos, para luego recuperarse en los años posteriores. 
La media y la mediana reflejan una inmigración más reciente en comparación con el total de inmigrantes, producto del peso que tenían los inmigrantes llegados en los diez años anteriores al levantamiento del padrón.

Tabla 21. Población nacida en el interior y total de inmigrantes con años de residencia registrados. Porcentaje, media y mediana. Ciudad de Buenos Aires. 1827. Fuente: Elaboración propia en base a: Archivo General de la Nación: Sala X 23-5-5 y 23-5-6.

\begin{tabular}{lcc}
\hline Años de residencia & Interior & Total inmigrantes \\
\hline 0 a 4 & 30,1 & 25,6 \\
5 a 9 & 20,1 & 14,1 \\
10 a 14 & 17,7 & 14,7 \\
15 a 19 & 9,3 & 11,2 \\
20 y más & 22,8 & 34,4 \\
\hline \multirow{2}{*}{ Total } & 100,0 & 100,0 \\
& $(2.270)$ & $(7.684)$ \\
\hline Media & & \\
Mediana & 11,9 & 15 \\
\hline
\end{tabular}

\section{Migrantes limítrofes \\ Composición interna}

La inmigración proveniente de los actuales países limítrofes estuvo presente en la ciudad de Buenos Aires, incluso desde el siglo XVIII, manteniendo un flujo migratorio relativamente estable que incluso se ha prolongado hasta la actualidad. A la hora de analizar esta categoría, nos surgen algunas dudas metodológicas, dado que en 1827 las Provincias Unidas reconocían a la Banda Oriental como parte de su territorio. Además, tanto Paraguay como el Alto Perú (Bolivia) habían formado parte del Virreinato del Río de la Plata y fueron reclamados por las Provincias Unidas durante la década de 1810, cuando estos territorios estaban en manos de los realistas. Finalmente, la sucesión de victorias y derrotas del Ejercito Patriota marcarían de hecho gran parte de los límites, quedando el Alto Perú y Paraguay en manos españolas. ${ }^{31}$

De este modo la diferencia entre migración interna y limítrofe se nos hace algo difusa. Sin embargo, a fin de no confundirnos, ni confundir al lector, preferimos mantener como dentro de la categoría "migrantes limítrofes" a quienes provenían de los países que actualmente limitan con la Argentina.

En cuanto a los fríos números, podemos observar en el Gráfico 13 que los orientales eran una amplia mayoría, seguidos de paraguayos, chilenos y brasileños, en ese orden, con un porcentaje menor. Finalmente, con menos del 5\%, aparecían los altoperuanos. 


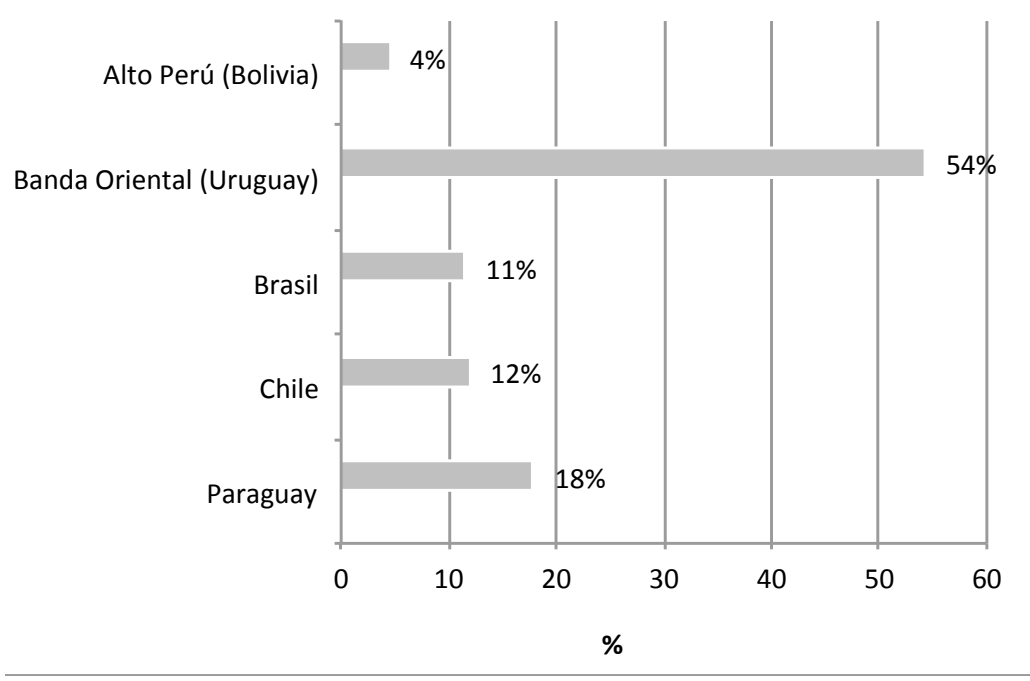

Gráfico 13. Composición de la población limítrofe. Ciudad de Buenos Aires, 1827 (en porcentaje). Fuente: Elaboración propia en base a: Archivo General de la Nación: Sala X 23-5-5 y 23-5-6. Total: 1.654.

\section{Estructura de sexo y edad}

Los inmigrantes limítrofes presentaban una relación de masculinidad algo más equilibrada que el total de inmigrantes, aunque con cierta preeminencia masculina. La edad media y mediana eran levemente inferiores. En lo que respecta a la estructura según sexo y edad presenta un cariz particular, ya que entre la población menor de treinta años predominaban las mujeres, mientras que la población mayor de treinta se encontraba compuesta por mayoría de varones. De alguna manera pareciera haber habido un flujo migratorio antiguo en el que predominaban los varones, mientras que los más recientes tenían una mayor presencia femenina. Es posible que el contexto de guerra permanente, a partir de 1806, haya ejercido un clima ciertamente contrario a la presencia de varones de baja condición social en la ciudad y la campaña de Buenos Aires, debido a que eran pasibles de ser reclutados por la leva (Tabla 22 y Gráfico 18).

Tabla 22. Relación de masculinidad, edad media y edad mediana de la población limítrofe y el total de inmigrantes. Ciudad de Buenos Aires. 1827. Fuente: Elaboración propia en base a: Archivo General de la Nación: Sala X 23-5-5 y 23-5-6.

\begin{tabular}{lccc}
\hline Origen & $\begin{array}{c}\text { Relación de } \\
\text { masculinidad }\end{array}$ & Edad Media & Edad Mediana \\
\hline Limítrofes & 113,7 & 32,6 & 30 \\
Total inmigrantes & 163,3 & 35,2 & 32 \\
\hline
\end{tabular}

Total: Limítrofes: 1.637 casos, sin datos: 17 casos. Total inmigrantes: 11.790 casos, sin datos: 125 casos. 


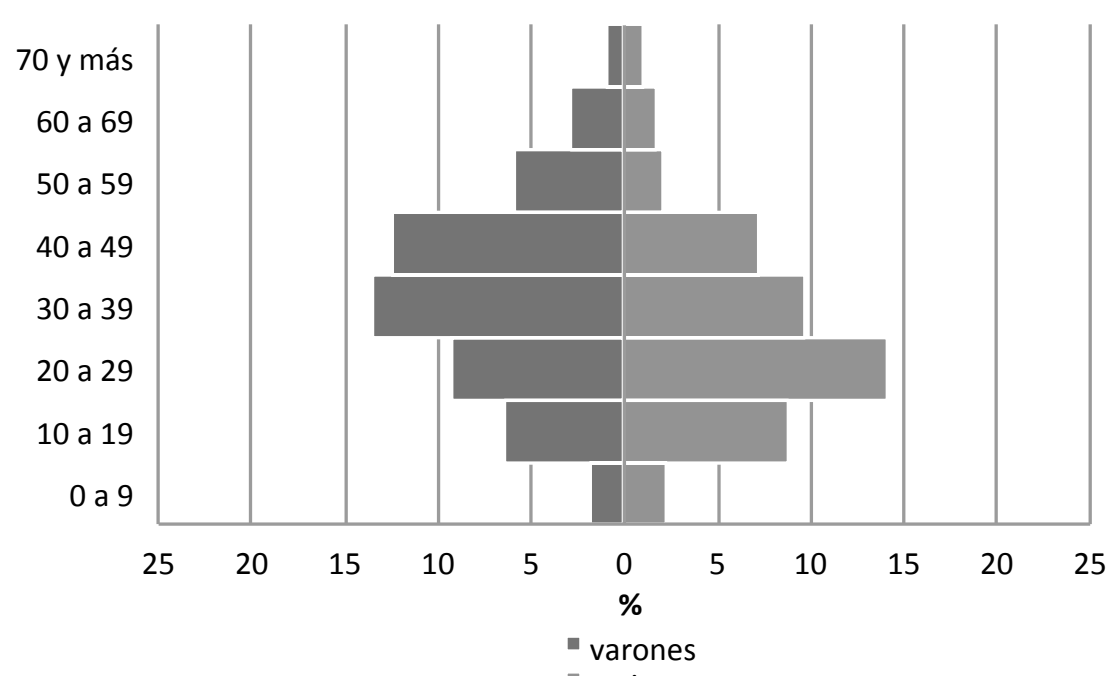

Gráfico 14. Población limítrofe según sexo y edad. Ciudad de Buenos Aires, 1827. Fuente: Elaboración propia en base a: Archivo General de la Nación: Sala X 23-5-5 y 23-5-6. Total: 1.637 casos, sin datos: 17 casos.

\section{Distribución espacial}

Los inmigrantes limítrofes presentaban una distribución espacial que evidentemente seguía la tendencia del total de los inmigrantes, aunque tenían una representación bastante menor en el área céntrica (Tabla 23).

Tabla 23. Distribución espacial de la población limítrofe y el total de inmigrantes. Ciudad de Buenos Aires, 1827. Fuente: Elaboración propia en base a: Archivo General de la Nación: Sala X 23-5-5 y 23-5-6.

\begin{tabular}{lcc}
\hline Zona & Limítrofes & Total Inmigrantes \\
& $\%$ & $\%$ \\
\hline Centro & 38,2 & 43,6 \\
Intermedia & 31,7 & 28,7 \\
Periferia & 19,4 & 17,3 \\
Semi rural & 10,7 & 10,4 \\
\hline Total & 100,0 & 100,0 \\
& $(1.652)$ & $(11.882)$ \\
\hline
\end{tabular}

Sin datos: Limítrofes: 2 casos, total inmigrantes: 33 casos.

\section{Estructura socio ocupacional}

La distribución de la estructura socio ocupacional era similar a la observada en el total de inmigrantes, aunque en comparación, los inmigrantes limítrofes presentaban un porcentaje menor entre las categorías relacionadas con los sectores económicos más beneficiados, mientras que por el contrario estaban sobre representados entre los empleados (III) y los trabajadores de menor calificación (V) (Tabla 24). 
Tabla 24. Población limítrofe y total de inmigrantes de 10 años o mas con ocupación relevada según categoría socio ocupacional. Ciudad de Buenos Aires. 1827. Fuente: Elaboración propia en base a: Archivo General de la Nación: Sala X 23-5-5 y 23-5-6.

\begin{tabular}{lcc}
\hline Categoría socio ocupacional & Limítrofes & Total Inmigrantes \\
\hline I & 7,5 & 9,2 \\
II & 12,1 & 20,6 \\
III & 7,2 & 3,7 \\
IV & 30,5 & 34,4 \\
V & 42,7 & 32,1 \\
\hline \multirow{2}{*}{ Total } & 100,0 & 100,0 \\
& $(692)$ & $(5.651)$ \\
\hline
\end{tabular}

I: Grandes comerciantes, hacendados, funcionarios y profesionales

II: Comerciantes pequeños y medianos

III: Empleados públicos (civiles y militares), eclesiásticos y privados

IV: Trabajadores Manuales Calificados y labradores

V: Trabajadores Manuales Calificados aprendices, Trabajadores Manuales no calificados, puesteros y comercio al menudeo, y Trabajadores Rurales.

Nota: en el total de inmigrantes decidimos incluir a 10 niños menores de 10 años que tienen ocupación declarada y en el total de inmigrantes limítrofes incluimos a 1 niño menor de 10 años con ocupación declarada.

\section{Años de residencia en la ciudad}

La inmigración proveniente de los actuales países limítrofes presentaba algunas oscilaciones en cuanto a la distribución porcentual de los años de residencia en la ciudad. No obstante observamos dos corrientes, una reciente en los cinco años anteriores al padrón, y otra de mayor número relativo que abarca la etapa colonial. Se sumaría una tercera que llegaría a la ciudad entre 1813 y 1817. Las oscilaciones que presenta esta categoría nos dificulta la posibilidad de sacar conclusiones; no obstante, destacamos que se trataba de una corriente migratoria estable (los datos que presentan la media y la mediana así lo indican), con una participación importante en la etapa anterior a la Revolución de Mayo, a la vez que manifestaba un fuerte descenso durante el período de mayor conflictividad (1808-1812), para luego recuperarse en años posteriores (Tabla 25).

Tabla 25. Población limítrofe y total de inmigrantes con años de residencia registrados. Porcentaje, media y mediana. Ciudad de Buenos Aires, 1827. Fuente: Elaboración propia en base a: Archivo General de la Nación: Sala X 23-5-5 y 23-5-6.

\begin{tabular}{lcc}
\hline Años de residencia & Limítrofes & Total inmigrantes \\
\hline 0 a 4 & 22,9 & 25,6 \\
5 a 9 & 12,3 & 14,1 \\
10 a 14 & 22,5 & 14,7 \\
15 a 19 & 10,6 & 11,2 \\
20 y más & 31,7 & 34,4 \\
\hline \multirow{2}{*}{ Total } & 100,0 & 100,0 \\
& $(993)$ & $(7.684)$ \\
\hline Media & & \\
Mediana & 14,7 & 15 \\
\hline
\end{tabular}




\section{Conclusiones}

Hacia 1827 la población de Buenos Aires contaba con una estructura de población fuertemente feminizada. ${ }^{32}$ En este contexto, es de fundamental importancia la presencia de los inmigrantes, sobre todo si tomamos en cuenta a los varones en edad activa. De esta manera, contribuían a reducir el desequilibrio entre los sexos observado en la baja relación de masculinidad que presenta la población nativa.

El principal aporte lo observamos entre la población ocupada, dado que los inmigrantes componían el 53\% de la mano de obra efectivamente ocupada. En una situación en la que parte de la población nativa de varones en edad activa parece haber sido absorbida por el ejército, la población inmigrante podría compensar en parte la ausencia de población nativa.

La población inmigrante superaban el cuarto de la población total de la ciudad, destacándose los migrantes: europeos, internos y africanos. Observamos también una tendencia a la diversificación de la procedencia inmigratoria, que se irá consolidando a lo largo del siglo XIX.

Españoles y africanos eran quienes presentan una población más envejecida. En ambos casos, se trataba de corrientes migratorias antiguas, que se remontaban a la etapa colonial. Al contrario de lo señalado en algunos estudios anteriores, creemos que la población inmigrante de la ciudad de Buenos Aires tendía a ser relativamente estable, dado que la media y la mediana de años de residencia en la ciudad superaban con creces los diez años. Es posible apreciar que existían dos corrientes mayoritarias, una registrada en la etapa colonial que terminaría con el conflictivo período de la Revolución de Mayo, y una segunda que se iniciaría en los años anteriores al padrón de 1827, durante la etapa de la Feliz Experiencia.

En la representación socio laboral, los españoles y europeos eran quienes, de alguna manera, estaban más "visibilizados" por el amanuense, dado que conforman el 53\% de los inmigrantes con ocupación registrada, a pesar de que componían el 35\% de la población inmigrante..$^{33}$ El hecho de que el resto de los inmigrantes que registraron ocupación tuvieran una representación ciertamente menor, nos permite inferir que, a los ojos del censista, los inmigrantes españoles y europeos tenían una evaluación socio laboral diferente al resto de los inmigrantes.

32 Es altamente probable que la falta de varones se haya observado particularmente en 1825 y 1828 por los efectos de la leva, la huida y el ocultamiento de varones. No obstante, en padrones anteriores y posteriores, la relación de masculinidad tendía a ser más equilibrada. Mientras que en 1827, la relación era de 81 varones por cada cien mujeres, en 1822 era de 91, y en 1855, de 96 (Massé, 1992). 
Más allá del señalado clima antipeninsular posterior a la Revolución de Mayo, pudimos constatar entre los españoles un importante sector relacionado con el gran comercio. De alguna manera, el clima contrario afectó menos de lo esperado a estos sectores acomodados de la comunidad española, que debido a la herencia del período colonial pudieron permanecer dentro de los sectores más privilegiados de la sociedad porteña.

Aún cuando el período de la inmigración masiva (1880-1915) es el más conocido por la historiografía relativa a la inmigración en Argentina, los resultados de nuestro trabajo -junto con otras investigaciones que toman el período anterior a la inmigración masiva ${ }^{34}$ - permite entrever que ya desde las primeras décadas del siglo XIX, la población porteña se caracterizó por su cariz cosmopolita y la relevancia de los inmigrantes en su estructura económica. 


\section{Bibliografía}

" Andrews, G.R. (1989). Los afroargentinos de Buenos Aires. Buenos Aires: De la Flor.

" Assadourian, C.S. \& Palomeque, S. (2014). "Los circuitos mercantiles del "interior argentino" y sus transformaciones durante la guerra de la independencia. (18101825). Cuadernos de Historia. Serie Economía y Sociedad. Universidad Nacional de Córdoba. https://revistas.unc.edu.ar/index.php/cuadernosdehistoriaeys/article/ viewFile/11282/11813

" Besio Moreno, N. (1939). Buenos Aires, Puerto del Río de la Plata, capital de la Argentina, estudio crítico de su población, 1536-1936. Buenos Aires.

" Bjerg, M. y Otero, H. (1995). Inmigración y redes sociales en la Argentina moderna. Tandil: CEMLa-IEHS.

" Chackiel, J. (2009, junio). Evaluación y estimación de la cobertura en los censos de población: La experiencia latinoamericana. Trabajo presentado en el taller del grupo de trabajo de la Conferencia Estadística de las Américas (CEA) y la Comisión Económica para América Latina (CEPAL). CEPAL, Santiago de Chile, 3, 4 y 5 de junio.

"Devoto, F. y Benencia, R. (2003). Historia de la inmigración en la Argentina. Buenos Aires: Sudamericana.

" Devoto, F. (2007). La inmigración de ultramar. En: Torrado, S. (Comp.). Población y bienestar en la Argentina del primero al segundo centenario. Una historia social del siglo $X X$. Tomo I. Serie Estudios del Bicentenario. Buenos Aires: ADHASA.

" Díaz, M. (1997 y 1998). Las migraciones internas a la ciudad de Buenos Aires, 1744-1810 (pp. 7-31). Boletín del Instituto de Historia Argentina y Americana "Dr. Emilio Ravignani", Tercera serie, núms. 16 y 17, Buenos Aires.

" Díaz, M. (2003). Migrantes en Buenos Aires: familia y cambio social, 1744-1810. Tesis de doctorado en historia. Facultad de Filosofía y Letras, Universidad de Buenos Aires

"Di Meglio, G. (2006). Viva el bajo pueblo!: la plebe urbana de Buenos Aires y la política entre la Revolución de mayo y el rosismo, 1810-1829. Buenos Aires: Prometeo Libros.

" Dmitruk, L.P. (2011). Porteños, migrantes, estructura socio ocupacional y ciclo de vida en la Ciudad de la Santísima Trinidad y Puerto de Santa María del Buen Ayre, 1810-1827, Tesis de licenciatura, Buenos Aires: Universidad de Buenos Aires, Facultad de Filosofía y Letras.

" Dmitruk, L.P. (2014a). Estructura socio ocupacional de la Ciudad de Buenos Aires post colonial. 1810 y 1827. Coordenadas. Revista de Historia Local y Regional. Volumen 1, núm 2. Río Cuarto: Universidad Nacional de Río Cuarto.

" Dmitruk, L.P. (2014b). Migrantes en la ciudad. Población y migraciones en la Ciudad de Buenos Aires. 1827. Trabajo presentado en: XXIV Jornadas de Historia Económica Argentina, Universidad Nacional de Rosario, Rosario, 1, 2 y 3 de Octubre.

"Dmitruk, L.P. (2017). Evaluación de la cobertura y el contenido en censos protoestadísticos: el caso del padrón de la ciudad y la campaña de Buenos Aires de 1827. Notas de Población. Julio-Diciembre, año XLIV, núm 105, p. 133-164. http://repositorio. cepal.org/handle/11362/43164

" Farberman, J. (1992). Migrantes y soldados. Los pueblos indios de Santiago del Estero en 1786 y 1813. Cuadernos del Instituto de Historia Argentina y Americana Dr. Emilio Ravignani. núm, 4. Buenos Aires: Facultad de Filosofía y Letras. 
" Fradkin, R.O. (2006), Historia de una montonera: bandolerismo y caudillismo en Buenos Aires. 1826, Buenos Aires, Siglo XXI Editores.

"Fradkin, R., Canedo, M., Mateo, J., (comp.) (1999). Tierra, población y relaciones sociales en la campaña bonaerense, siglos XVIII y XIX. Mar del Plata: UNMdP.

" Garavaglia, J.C. (1999). Pastores y labradores de Buenos Aires. Buenos Aires: Ediciones De la Flor.

" Garavaglia, J.C., y Moreno, J.L., (comp.) (1993). Población, sociedad, familia y migraciones en el espacio rioplatense. Siglos XVIII y XIX. Buenos Aires: Cántaro.

" Garcia Belsunce, C.A. (coord) (1976). Buenos Aires, 1800-1830. Buenos Aires: Emecé.

" Gelman, J. (1998). Campesinos y Estancieros. Una región del Río de la Plata a fines de la época colonial. Buenos Aires: Los libros de Riel.

" Goldberg, M. (1976). La población negra y mulata de la ciudad de Buenos Aires, 18101840. Desarrollo Económico, v. 16, núm. 61.

" González Bernaldo, P. (2001). Civilidad y política en los orígenes de la nación Argentina: la sociabilidad en Buenos Aires 1829-1862. Buenos Aires: Fondo de Cultura Económica.

" Guzmán, T. (2012, octubre). La estructura ocupacional y la economía urbana de Buenos Aires hacia 1827. Trabajo presentado en: III Congreso Latinoamericano de Historia Económica y XXIII Jornadas de Historia Económica Argentina, Universidad Nacional del Comahue, San Carlos de Bariloche, del 23 al 27 de octubre.

" Halperin Dongui, T. (1979). Revolución y guerra. México: Siglo XXI.

" Halperin Donghi, T. (1985). Reforma y disolución de los imperios ibéricos: 1750-1850, Historia de América Latina, 3. Madrid: Alianza.

" Johnson, L. (1979). Estimaciones de la población de Buenos Aires en 1774, 1778 y 1810. Desarrollo Económico, v. 19, núm. 73.

" Johnson, L y Socolow, S. (1980). Población y espacio en el Buenos Aires del siglo XVIII. Desarrollo Económico, v 20, núm. 79.

" Moreno, J.L. (1965). La estructura social y demográfica de la ciudad de Buenos Aires en el año 1778. Anuario del Instituto de Investigaciones Históricas, núm. 8.

" Moreno, J. L. y Mateo, J. (1997). El redescubrimiento de la demografía histórica en la historia económica y social. Anuario IEHS, núm. 12. Tandil.

" Massé, G. (1992). Reinterpretación del fenómeno migratorio y su incidencia en la conformación socio-demográfica de la ciudad de Buenos Aires a mediados del siglo XIX. Tesis de Maestría en Demografía Social, Universidad Nacional de Luján.

" Massé, G. (2006). Inmigrantes y nativos en la ciudad de Buenos Aires al promediar el siglo XIX. Población de Buenos Aires, año 3, nro. 4, 9-25. Dirección General de Estadística y Censos del Gobierno de la Ciudad Autónoma de Buenos Aires.

" Massé, G. (2012) El tamaño y el crecimiento de la población desde la Conquista hasta 1870. en: Otero, H. (Coord.) Historia de la provincia de Buenos Aires. Buenos Aires: EDHASA-UNIPE.

" Mateo, J. (1993). Migrar y volver a migrar: Los campesinos agricultores de la frontera bonaerense a principios del siglo XIX. En Garavaglia, J.C., y Moreno, J.L., (comp.). Población, sociedad, familia y migraciones en el espacio rioplatense. Siglos XVIII y XIX. Buenos Aires: Cántaro.

"Mateo, J. (1999). Pequeños ranchos sobre la pampa. La población en la colonización de la frontera de Buenos Aires. San Salvador de Lobos, 1810-1869. En Fradkin, R., Canedo, 
M., Mateo, J., (comp.). Tierra, población y relaciones sociales en la campaña bonaerense, siglos XVIII y XIX. Mar del Plata: Universidad Nacional de Mar del Plata.

" Mazzeo, V. (1993). Mortalidad infantil en la ciudad de Buenos Aires (1856-1986). Buenos Aires: Centro Editor de América Latina.

"Otero, H. (dir.). (2004). El mosaico argentino. Modelos y representaciones del espacio y de la población, siglos XIX y XX. Buenos Aires: Siglo XXI.

" Otero, H. (2007). Censos antiguos: 1869, 1895, 1914, 1947. En: Torrado, S. (Comp.). Población y bienestar en la Argentina del primero al segundo Centenario. Una historia Social del Siglo XX. Tomo I, Serie Estudios del Bicentenario. Buenos Aires: EDHASA.

" Pantelides, E. A. (1992). Más de un siglo de fecundidad en la Argentina: su evolución desde 1869. En: Notas de Población, año XX. N. 56, Santiago de Chile: CELADE.

" Ravignani, E. (1919). Crecimiento de la población en Buenos Aires y su campaña (17261810). Facultad de Ciencias Económicas, Anales, T. 1.

" Recchini de Lattes, Z. (1971). La población de Buenos Aires. Buenos Aires: Ins.

"Santilli, D. V. (2000). Población y relaciones en la inmediata campaña de la ciudad de Buenos Aires. Un estudio de caso: Quilmes 1815-1840. Anuario del Instituto de Estudios Histórico-Sociales, núm. 15, Tandil.

"Somoza, J. (1971). La mortalidad en la Argentina entre 1869 y 1960. Buenos Aires: Instituto Torcuato Di Tella-Celade.

"Szuchman, M.D. (1988). Order, Family, and Community in Buenos Aires, 1810-1860. Stanford: Stanford University Press.

" República Argentina. (1872). Primer Censo Nacional de Población de la República Argentina. 1869. Buenos Aires.

"Ternavasio, M., (2000). Las reformas rivadavianas en Buenos Aires y el Congreso General Constituyente (1820-1827). En: Goldman, N. (Dir.). Revolución, República, Confederación: 1806-1852, Nueva historia argentina, 3. Buenos Aires: Sudamericana.

" Tratado de Amistad, Comercio y Navegación celebrado entre las Provincias Unidas del Río de la Plata y Su Majestad Británica (1825). http://www.lagazeta.com.ar/tratado_de_1825. htm\#11 (consultada el 23/03/2018). 